\title{
Experimental tests and numerical simulations of circular reinforced concrete piers under ship impact
}

\author{
Zhiyue Chen ${ }^{1}$, Hai Fang ${ }^{1 *}$, Lu Zhu' ${ }^{1}$ Yifeng Mao ${ }^{2}$ and Weiqing Liu ${ }^{1}$
}

\author{
* Correspondence: fanghainjut@163. \\ com \\ ${ }^{1}$ College of Civil Engineering, $\mathrm{Na}$ \\ njing Tech University, Nanjing \\ 211816, China \\ Full list of author information is \\ available at the end of the article
}

\begin{abstract}
A growing number of bridge structures spanning over waterways are most susceptible to ship-pier collisions that may result in serious consequences such as ship sinking, failure and collapse of the bridge, even personal casualty, etc. To quantify the impact force and load, ship-pier impact tests and reliable numerical predictions should be carried out. This paper shows experimental tests and numerical simulation results of ship impact on bridge piers. To assess the performance of circular reinforced concrete piers against ship collisions and guide the design of bridge piers against impact, reduced-scale circular reinforced concrete (RC) piers were built and tested, and finite element (FE) simulations based on edge pier of junction pier of Wu-Song River Bridge were also conducted. To evaluate the reasonability of the damage process and failure mode of the pier due to ship impact more accurately, the bridge piers are modeled with nonlinear materials to simulate the bridge pier characteristics instead of rigid and elastic materials. Based on numerical results, the design impact loads prescribed by code current specifications such as Eurocode and AASHTO Bridge Design Specifications were evaluated and compared. To predict impact force, the fiber section model was employed to attain ultimate bearing capacity of the pier.
\end{abstract}

Keywords: Ship-pier collision, Reduced-scale test, Numerical simulation, Impact force

\section{Introduction}

A significant number of bridges spanning navigable waterways are put into use all over the world, which are inherently subjected to various impact loads such as wind loads, vehicle loads, passing ship loads, etc. Among the impact loads, ship collisions are regarded as a significant issue as growing number of accidents accused by ship colliding with bridge piers in recent decades (AASHTO 2009; Consolazio and Cowan 2005; Fang et al. 2016a; Sherif et al. 2015). Ship collision with piers might lead to tremendous damage, even failure and collapse of bridges and personal casualty. Hence it is of importance to prevent and protect bridge piers from ship collision, which has been drawn great attentions.

Generally, there are mainly two approaches in studying the ship-pier collisions, i.e., experimental tests and numerical simulations. In order to quantify the impact load

(c) The Author(s). 2020 Open Access This article is licensed under a Creative Commons Attribution 4.0 International License, which permits use, sharing, adaptation, distribution and reproduction in any medium or format, as long as you give appropriate credit to the original author(s) and the source, provide a link to the Creative Commons licence, and indicate if changes were made. The images or other third party material in this article are included in the article's Creative Commons licence, unless indicated otherwise in a credit line to the material. If material is not included in the article's Creative Commons licence and your intended use is not permitted by statutory regulation or exceeds the permitted use, you will need to obtain permission directly from the copyright holder. To view a copy of this licence, visit http://creativecommons.org/licenses/by/4.0/. 
during ship collision, a number of ship collision tests were conducted. In 1959, Minorsky (Minorsky 1959) conducted the first ship collision test, who examined 26 experimental ship collision tests and proposed an empirical formula that relates the deformation of steel volume to impact energy. A large quantity of high energy ship collision tests were carried out by Woisin (Woisin 1976),who modified Minorsky's formula and also developed an empirical formula that relates the impact force and impact energy to ship deformation. Based on a practical bridge across the Quanzhou, Lin et al. (Lin et al. 2003) conducted the scaled model testing on the forces of ship collision, in which the impact force was compared with various code expressions. The results show that the design force of ship collision specified by AASHTO specifications is in good accordance with the testing results. However, the design force specified by current design specifications of highway bridge of China is obviously lower than the testing results. Consolazio et al. (Consolazio et al. 2005) conducted full scale barge impact tests on two bridge piers at the St. George Island Causeway Bridge in 2004. Based on a practical ship collision test, impact force, pier, soil and barge responses were recorded. However these applications are limited to the cases having similar conditions because in many cases the test data cannot be extrapolated. Demartino et al. (Demartino et al. 2017) studied responses of shear-deficient circular pier under lateral impact loading by scaled tests, and it revealed the high vulnerability of structural elements.

Although impact experiments are straightforward and obtain good impact force and pier displacement, they are usually costly and time-consuming. Thus, FE method is used as an alternative way to study the ship-pier collision. Consolazio and Cowan (Consolazio and Cowan 2003) used numerical simulations to study a single barge impacting against rigid square and circular piers in ADINA. The results show that the shape and size of the pier will affect the force-crush depth curves and that the barge impact force is related to factors other than the crush depth of the barge bow. El-Tawil et al. (El-Tawil et al. 2005) analyzed a RC pier under vehicle collision by using numerical simulation. The impact forces are much higher than the AASHTO-LRFD collision design force. Manuel et al. (Manuel et al. 2016) studied the impact force and the bearing capacity of the pier by using numerical simulation. The effects of impact velocity, the mesh size, impact position and material parameters on the ship impact force were considered and studied. In some studies, the piers were simply assumed to be rigid or elastic in the model. To predict the interaction between the ship and pier more accurately, nonlinear responses should be considered in the numerical simulation. Zhao et al. (Zhao and Qian 2019) employed numerical simulation technique and established three-dimensional finite element models of a prototype RC pier under lateral impact. A new damage assessment method based on the sectional damage factor was presented to determine the damage level of RC. The numerical model that considers the nonlinear pier material properties is developed in LS-DYNA (LSTC 2007). Very good agreement is observed between the experimental and numerical results. Sha and Hao (Sha and Hao 2012) developed a detailed numerical model of barge-pier collision in LS-DYNA, and based on the numerical results, developed empirical equations for prediction of barge crush depth and peak impact force based on barge impact kinetic energy. Wan et al. (Wan et al. 2019) studied the failure mode of the RC pier through the horizontal impact test and numerical simulation. The results shows the main failure mode of piers was bending-shear failure with localized concrete crushing. The pier was modelled with 
nonlinear materials to simulate the pier characteristics more realistically. Do et al. (Do et al. 2018) developed validated numerical models using LS-DYNA and analyzed the effectiveness of prestressing level, number of segments, concrete strength, and vehicle velocity on the behavior of precast segmental concrete columns. Sha et al. (Sha and Hao 2013) carried out scaled tests and numerical simulations of barge impact on circular RC piers, proposing empirical formulae to predict the peak impact force and impulse.

At present, the understanding of the ship-bridge collision mechanism is still insufficient, and the calculation results of ship collision design standards in different countries are quite different, especially the low value of the ship collision design standard of China's highway bridges, which poses a big hidden danger to the safety of bridge structures. Therefore, ship-bridge collision study was carried out based on the actual project about edge pier of junction pier of Wu-Song River Bridge. Nowadays, a number of studies on ship collision have mainly focused on the impact force, impact energy and dynamic response of pier (Tang and Hao 2010; Yang and Qiao 2010; Fang et al. 2016b; Travanca and Hao 2014). A few of studies have been emphasized on horizontal impact tests of piers. However, the horizontal impact tests of piers are the most straightforward approaches that give proper impact force measurements. In this paper, scaled model tests of ship collision and numerical simulations were carried out, and nonlinear FE models of ship and RC bridge pier were developed in the LS-DYNA. Then the pier was modeled with nonlinear concrete and steel materials to generate more realistic pier characteristics. The objective of this paper is to study impact forces on bridge piers under different impact velocities. In the light of experimental and numerical results, the design impact loads prescribed by the Chinese bridge design code, Eurocode and AASHTO LRFD Bridge Design Specifications will also be evaluated. The fiber section model was used with an amend factor, that considers confined action of spiral stirrups, advised in calculation of pier collision resistance. Therefore, the impact velocities and pier collision resistance should be considered comprehensively in the anti-collision design of circular piers, so as to ensure the reliability and safety of the structure.

\section{Horizontal impact tests of ship-pier collision}

Taking ship-bridge collision as engineering background, this chapter simplifies approach pier and auxiliary pier into cantilever pier-column model under vertical force, and studies the impact force and the dynamic response of pier under lateral impact load through experiments which include different impactors impacting on axially loaded circular reinforced concrete piers.

\subsection{Test design}

\subsubsection{The ship and ship bow model}

According to the Buckingham $\pi$ theorem and dimensional analysis, the similarity coefficient of the test model for ship-bridge impact test is determined. The design impact ship (total tonnage is 1489.9 tons) was 1000 DWT in these tests. The geometry of ship model was scaled in 1:10, with the cart weight of 1.475 tons and the bow weight of 0.0154 tons. 
The ship bow model, which was made of Q235 cold-rolled ordinary thin steel plate with a thickness of $1 \mathrm{~mm}$, was consisted of outer panels, the inner transverse diaphragm, decks and other components. However, it is very difficult to make inner structure of the ship bow model the same as that of the real ship bow. Therefore, inner structure of the ship bow was equivalently simplified by using four diaphragm plates with the same stiffness. The details of the size of the ship bow are shown in Fig. 1, and the ship bow model is shown in Fig. 2. Outer panels and the inner transverse diaphragm of ship bow model were connected by argon arc welding.

\subsubsection{The RC pier model}

The pier model is based on the side pier of Wu-Songjiang Bridge junction pier, which is navigable 1000DWT barge. The design dimensions of piers are shown in Fig. 3. The similarity ratio of the model is $1: 10$, which is reduced by linear stiffness with the original pier. The diameter of the prototype pier is $3 \mathrm{~m}$ and the pier height is $12.64 \mathrm{~m}$. As the similarity ratio of the model is $1: 10$, the height of pier model is $1.5 \mathrm{~m}$ and the diameter of model pier is $0.3 \mathrm{~m}$. The reinforcement and cast-in-place of the pier model are shown in Fig. 4, respectively. The concrete material and all reinforced bars of the bridge model are C40 and HRB335, respectively. $\Phi 10$ reinforcement bars are employed for longitudinal main reinforcement, and $\Phi 6$ plain round bars are employed for the stirrups and spacer bars. Three prismatic test blocks and three cubic test blocks, which are maintained under the same conditions as the pier model, are reserved in the process of pouring pier according to the specifications. In addition, two longitudinal reinforcement and stirrup samples are reserved. The compressive modulus and compressive strength of the reserved concrete blocks tested on a pressure testing machine are $44.18 \mathrm{MPa}$ and $34.9 \mathrm{GPa}$ respectively, and the Poisson ratio was 0.21 . The properties of reinforced materials are tested by a universal testing machine. The elastic modulus, yield strength and ultimate strength are $228.40 \mathrm{GPa}, 455.49 \mathrm{MPa}$ and $770.29 \mathrm{MPa}$, respectively. Material index of bridge pier model is listed in Table.1.

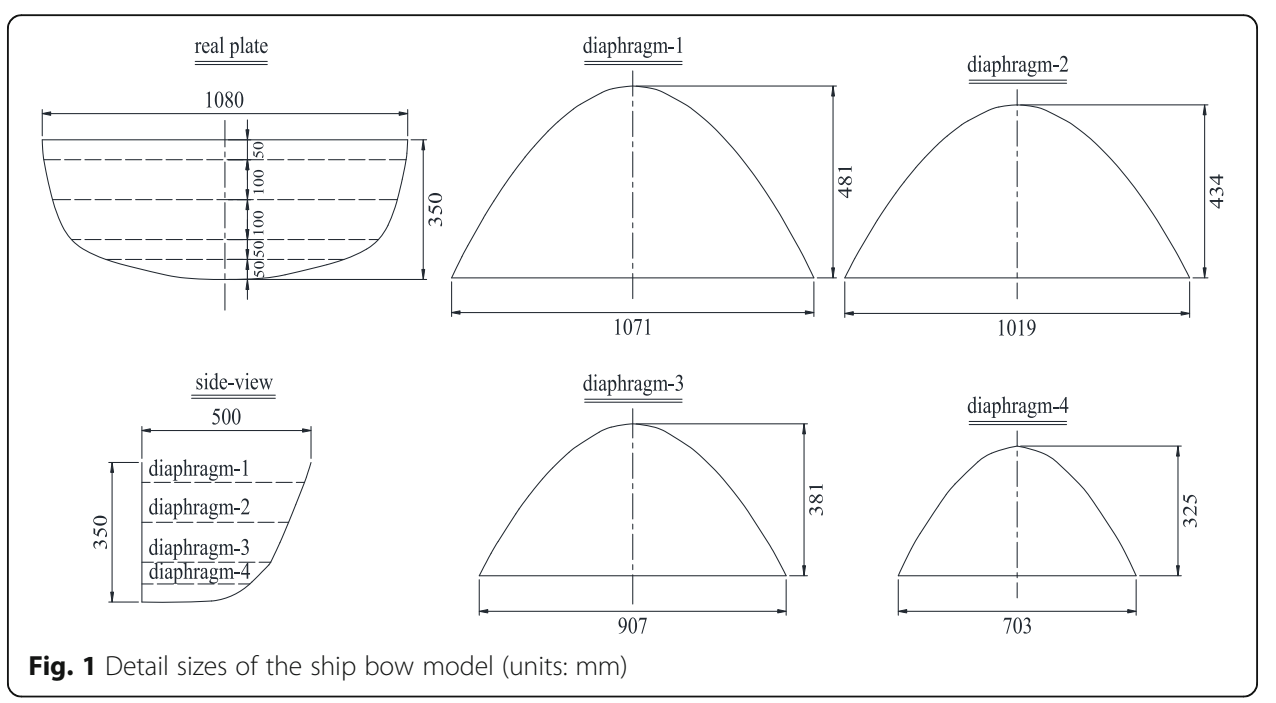




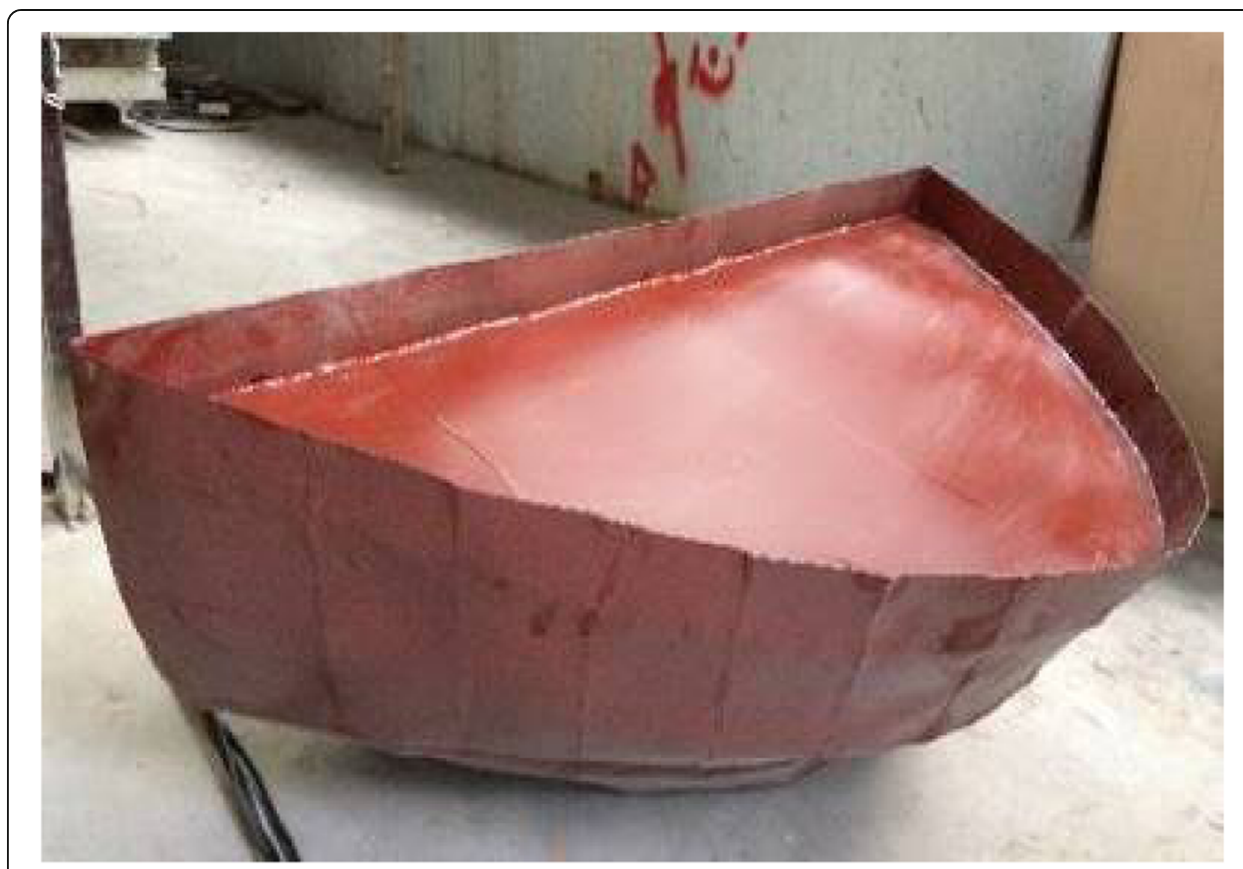

Fig. 2 Ship bow model

\subsection{Dynamic test device}

\subsubsection{Experimental facilities}

The horizontal impact tests were conducted by using the $230 \mathrm{KJ}$ impact test machine at Nanjing Tech University, which were performed by controlling the impact speed. The loading diagram is shown in Fig. 5. Horizontal impact testing machine was mainly composed of an impact cart, a guide rail, a reaction frame and a reaction wall. One end of the wire rope was hanging on the vertical ram, and the other end was connected with the cart-pulling device. The drop of the ram drove the cart-pulling device to accelerate the cart forward. As the cart reached the horizontal impact platform, the cartpulling device hit the decoupling buffer device, and at the same time the car instantaneously decoupled and collided with the circular reinforced concrete pier model. The horizontal impact speed of the cart could be controlled by raising the ram to a proper height. Five different conditions were taken into account in the horizontal impact tests: $4.2 \mathrm{~m} / \mathrm{s}$ for the ship bow and the rigid head impactor, and $1.11 \mathrm{~m} / \mathrm{s}, 2.08 \mathrm{~m} / \mathrm{s}$ and 3.01 $\mathrm{m} / \mathrm{s}$ for the rigid head. The specifications of the test conditions are listed in Table 2 .

\subsubsection{Impact test arrangement and data acquisition system}

After the pier model was hoisted to the design position, the high-strength bolts and bottom fixation of foundation pit were used to simulate the actual fixed-end constraint. The load of the upper structure was provided by the jack fixed on the reaction frame, which can provide relatively stable vertical axial force in the test. The vertical load provided by the jack, which was equivalent to a lumped mass on pier top to simulate the weight a pier supports, was 1.5 tons.

The pier model was hoisted to the horizontal impact test area and adjusted to the appropriate height through the prefabricated steel pads in the foundation pit. The center 


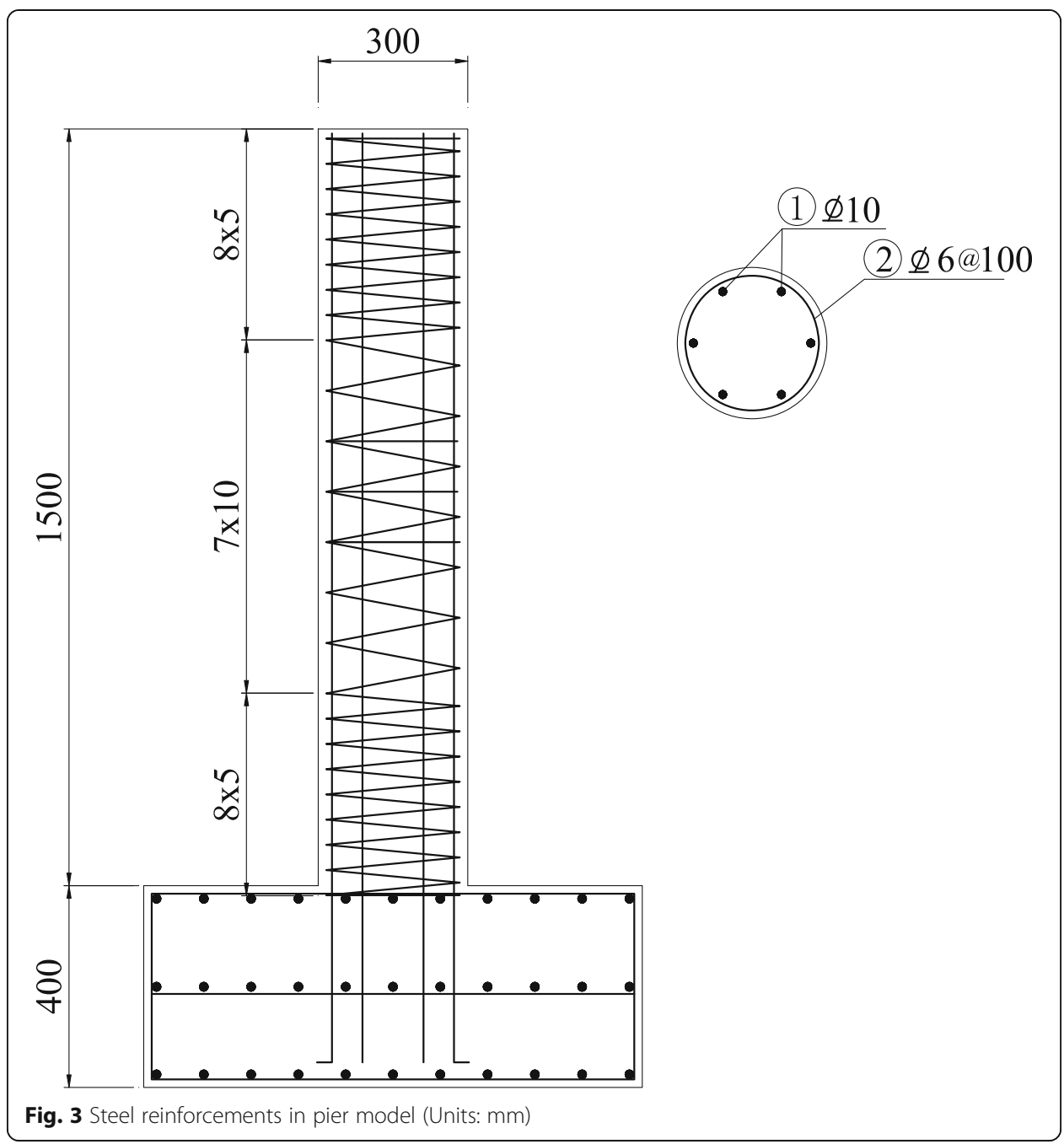

line of the pier was aligned with the center of the guide rail in the horizontal direction. After the pier specimen was placed in the design position, the base was fixed to the pre-buried hole at the bottom of the foundation pit with high-strength bolts, and the corresponding axial force was applied to the pier top by jack. Before the start of the test, the connection of all channels and the parameter settings of the acquisition instrument were checked, the strain gauges were tested whether they were in the initial equilibrium state, and a test impact operation on the whole impact system before the formal test was carried out to ensure the normal operation of the instrument and equipment. The impact test arrangement is shown in Fig. 6.

The impact force and the dynamic response of the pier are mainly collected in the test. The dynamic response includes the pier displacement. The collecting location is the impact point and the top and bottom of the pier. The test data acquisition system is consisted of a dynamic strain amplifier and multi-channels data acquisition equipment. There were two accelerometers and three displacement meters in tests. The data acquisition of each channel is as follows: velocity acquisition by double-beam laser measurement with accuracy class of 0.5 ; acceleration acquisition by arranging chargetype acceleration with inherent frequency of $1000 \mathrm{~Hz}$ in the key position of pier (middle 


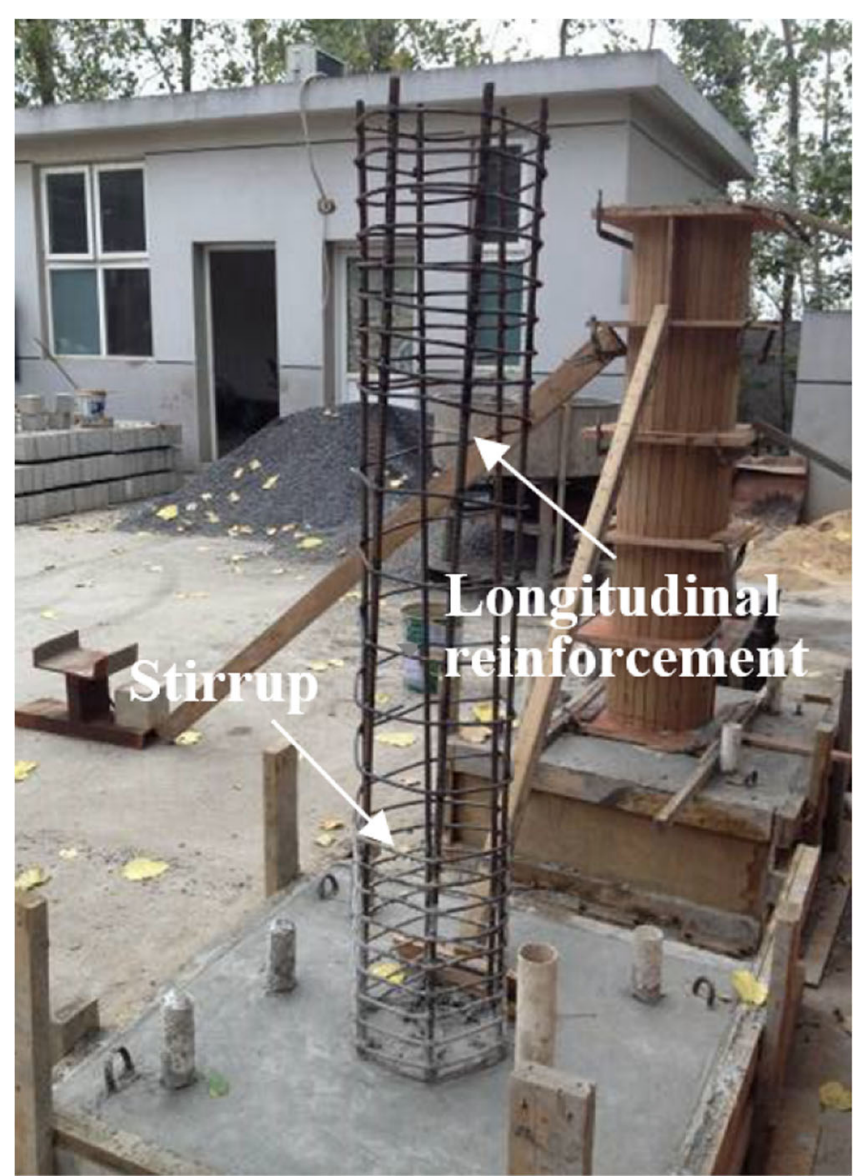

Fig. 4 Modeling of bridge pier

and top of pier); force acquisition by installing piezoelectric force sensors with accuracy class of 0.5 and inherent frequency of $200 \mathrm{KHz}$ between impact cart and impact body; displacement acquisition by arranging the pull rod displacement meter with a maximum measurement of $200 \mathrm{~mm}$ at the impact point and the top and bottom of pier to obtain the deformation of bridge model under impact force; the impact depth history and process acquisition by high-speed camera; and the strain gauge measuring points arranged at the key position of pier model to obtain the dynamic stress distribution with time under impact force.

Table 1 Material index of pier model

\begin{tabular}{lll}
\hline Material & Parameter & Magnitude \\
\hline Concrete & Young's modulus & $34.90 \mathrm{GPa}$ \\
& Compressive strength & $44.18 \mathrm{MPa}$ \\
& Poisson's ratio & 0.20 \\
Steel & Young's modulus & $228.40 \mathrm{GPa}$ \\
& Yield strength & $454.99 \mathrm{MPa}$ \\
& Ultimate strength & $770.29 \mathrm{MPa}$ \\
\hline
\end{tabular}




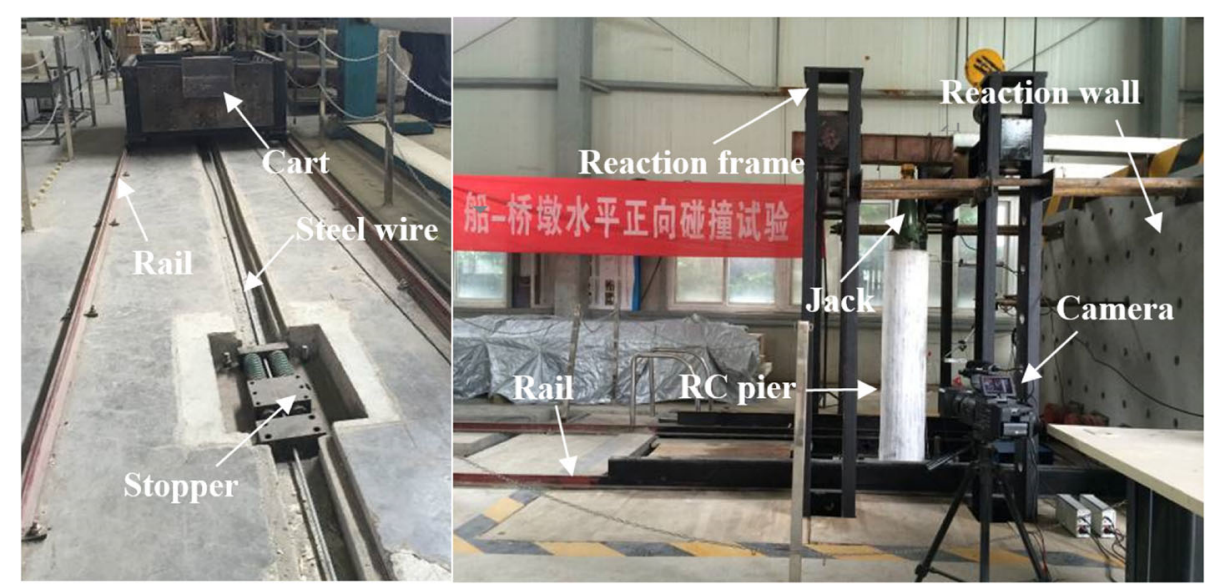

Fig. 5 Schematic diagram of impact model test

\subsection{Experimental results and analysis}

\subsubsection{Impact test arrangement and data acquisition system}

As shown in Fig. 7, when the cart speed of the bow model was $4.22 \mathrm{~m} / \mathrm{s}$, the peak impact force was $64.50 \mathrm{kN}$, and the peak displacement of the pier top was $7.96 \mathrm{~mm}$. As shown in Fig. 8, the bow tip was compressed and then deformed, and the buckling deformation occurred in the bow steel plate. Simultaneously, slight cracks appear at the foot of the pier and slight scratches occurred at the impact point of the pier.

\subsubsection{Rigid head impact on piers}

In order to study the effects of different impactors on impact force and pier displacement, four impact velocities of $1.11 \mathrm{~m} / \mathrm{s}, 2.08 \mathrm{~m} / \mathrm{s}, 3.01 \mathrm{~m} / \mathrm{s}$ and $4.15 \mathrm{~m} / \mathrm{s}$ for the rigid head were employed in this study. Figure 9 shows the impact force time history curves corresponding to the four impact velocities with the rigid heads.

As shown in Fig. 9, the peak impact force was $90.40 \mathrm{kN}$ when the cart impact velocity was $1.11 \mathrm{~m} / \mathrm{s}$. Although there were slight cracks at the foot of the pier and noticeable scratches at the impact point of the pier and, there was no damage to the pier. The peak impact force was $176.3 \mathrm{kN}$ when the cart impact velocity was $2.08 \mathrm{~m} / \mathrm{s}$. There were noticeable scratches and no obvious damage at the impact point of pier. Meanwhile, the collision surface cracked at the bottom of the bridge pier, and the cracks were noticeable and spread out to the side of the pier. The peak impact force was $148.70 \mathrm{kN}$ when the cart impact velocity was $3.01 \mathrm{~m} / \mathrm{s}$. There were two slight horizontal cracks on the back of the pier impact point. The cracks expanded the

Table 2 Test conditions

\begin{tabular}{llll}
\hline Label & Impactor & Impact velocity $(\mathrm{m} / \mathrm{s})$ & Test impact force $(\mathrm{kN})$ \\
\hline A-1 & Ship bow & 4.22 & 64.50 \\
B-1 & Rigid head & 1.11 & 90.40 \\
B-2 & Rigid head & 2.08 & 176.30 \\
B-3 & Rigid head & 3.01 & 148.70 \\
B-4 & Rigid head & 4.15 & 102.60 \\
\hline
\end{tabular}

Notes: The 1000 DWT ship is assumed to impact the narrow side of the pier 


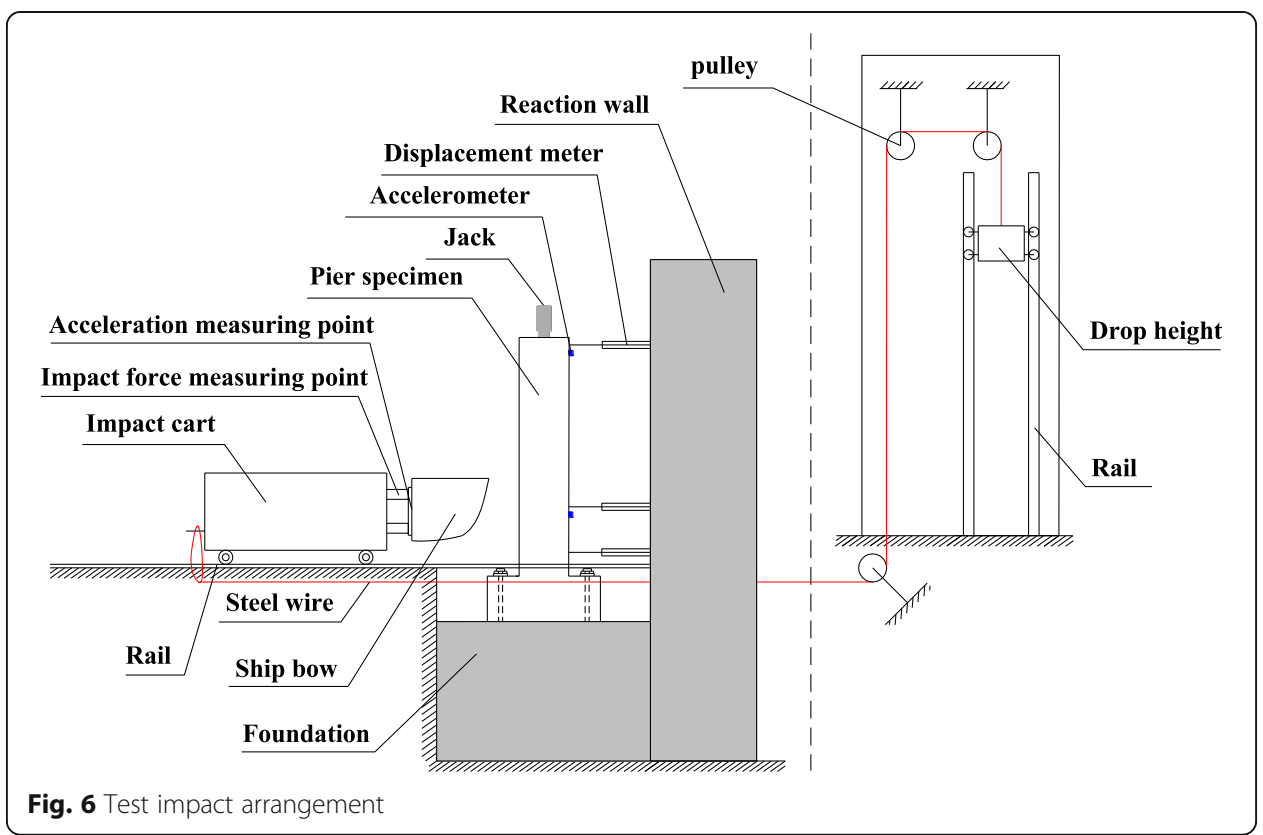

impact surface of the pier bottom, which were prominently perpendicular to the cracks, and expanded along the impact direction from the pier bottom. Due to the tensile failure of the longitudinal reinforcement and the bending failure of oblique section at the pier bottom, horizontal cracks appeared at the impact surface at about $10 \mathrm{~cm}$ above the pier bottom, which extended to the side of the pier to form subtle cracks. The concrete subjected to compression were spalled off and crushed at lateral surface of the pier bottom, therefore the impact force decreased with the increase of impact velocity.

When the cart impact velocity was increased to $4.15 \mathrm{~m} / \mathrm{s}$, the peak impact force was 102.60 $\mathrm{kN}$. Because of the plastic hinge at the pier bottom, the bending failure at the middle part of the pier and tension at the back of the impact point, two horizontal cracks developed obviously, and the cracks at the pier bottom continued to expand, meanwhile the width of the cracks continued to increase. Finally, the cracks at $20 \mathrm{~cm}$ above the pier bottom expanded prominently, which resulted in the pier failure and incline, so the pier produced irreversible deformation afterwards. The distribution of cracks in the final failure of specimens is shown in Figs. 10 and 11.

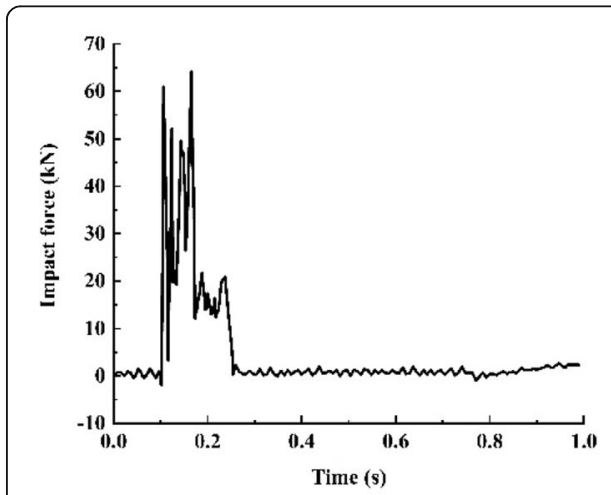

(a)

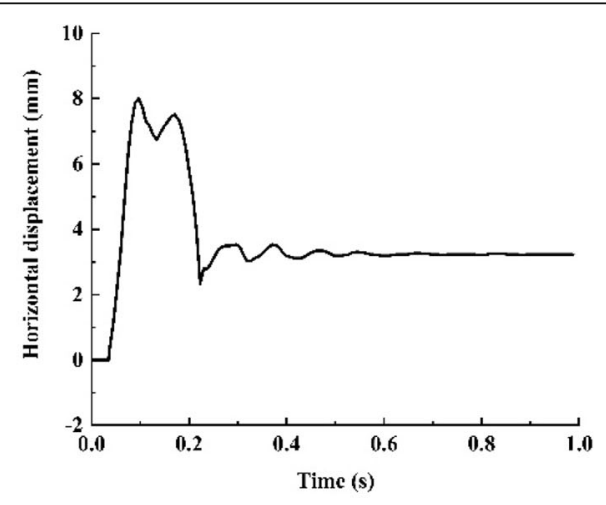

(b)

Fig. 7 Time history curve of impact force with bow collision: a impact force; $\mathbf{b}$ pier top displacement 


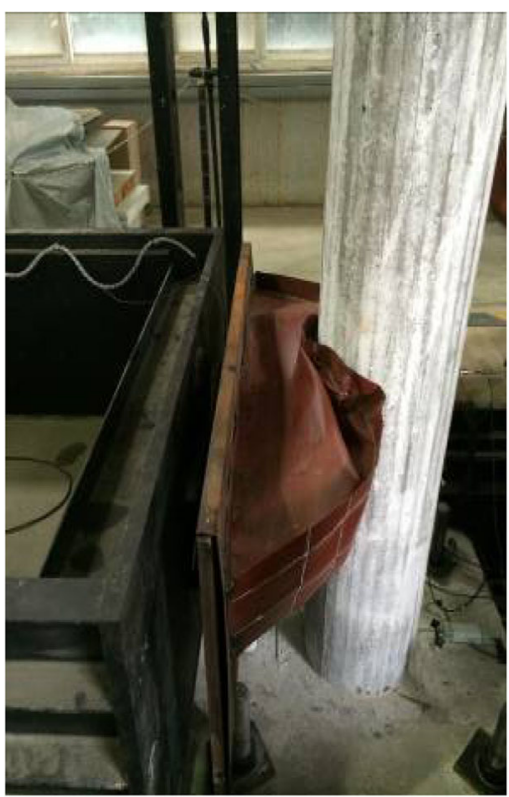

(a)

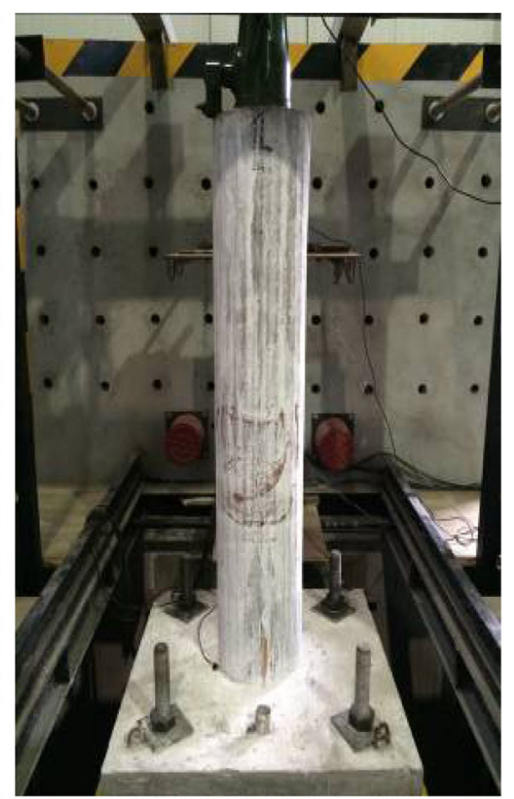

(b)

Fig. 8 Impact test phenomenon: a ship bow damage deformation; b pier with no obvious damage

\subsubsection{Test analysis and discussion}

When the impact velocities of the bow and the rigid head were approximate $4.2 \mathrm{~m} / \mathrm{s}$, the peak impact forces were $64.50 \mathrm{kN}$ and $102.60 \mathrm{kN}$, respectively, which was concluded that the impact force increased with the greater stiffness of the impactor. In addition, the bow impact time of $0.167 \mathrm{~s}$ was 2.1 times the rigid head impact time of $0.08 \mathrm{~s}$, which was concluded that the impact time was related to the stiffness of

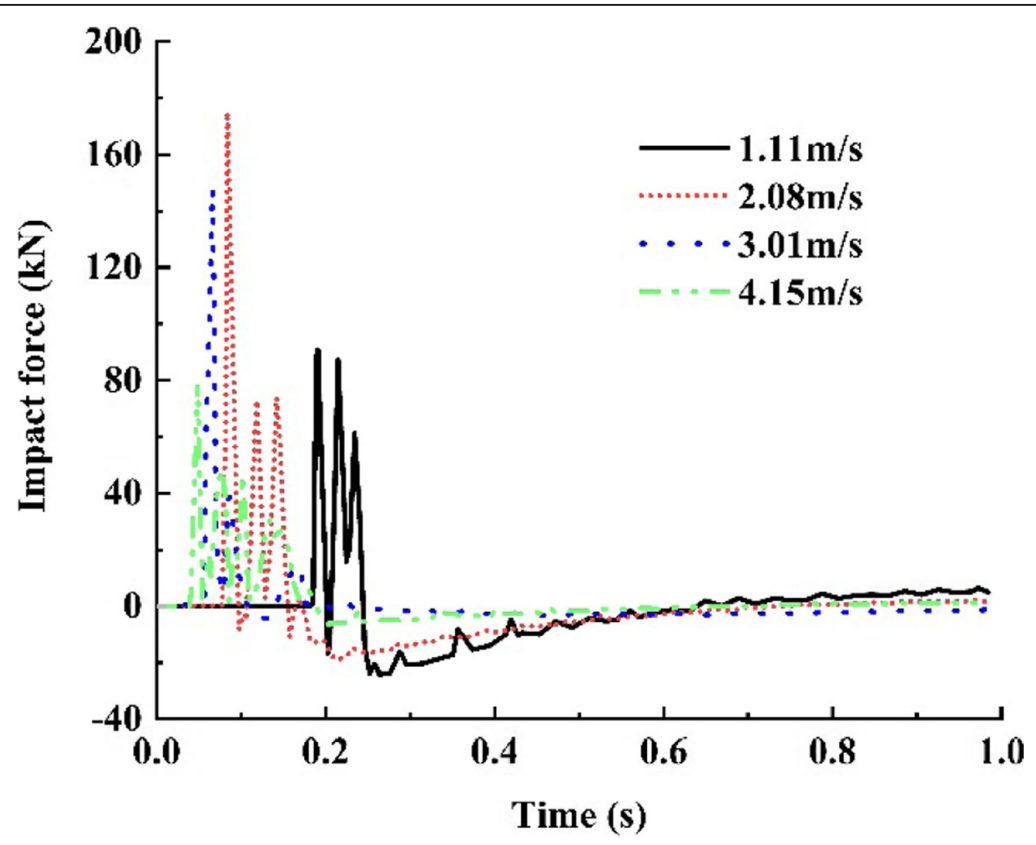

Fig. 9 Comparison of impact force corresponding to different impact velocities 
impactors and the impact duration became shorter with the greater impactor stiffness. For the same specimen, the impact time decreased with the increase of the impact energy. The pier top displacement and residual plastic deformation increased significantly with the increase of impact energy. When the impact velocity was $4.15 \mathrm{~m} / \mathrm{s}$, the peak value of pier top displacement accused by the pier failure was too large so that it exceeded the displacement meter range, which led to the distortion of the time history curves of pier top displacement, as shown in Fig. 12. When the pier reached the maximum deformation, the rebound deformation of the specimen occurred, which resulted in the decrease of pier top displacement after reaching the first wave peak. When the impact velocity is small, the displacement decreases to 0 . When the impact velocity is large, the pier had residual deformation.

Under the impact loading, the bending failure and local concrete crushing occurred mainly at the foot of circular RC pier. The first crack appeared at the foot of the pier where the value of the bending moment was the maximum. And the concrete cracked in tension, horizontal cracks appeared. The horizontal cracks continued to develop to both sides, and obvious through cracks appeared, the cracks expand along the direction of impact. Then longitudinal reinforcement at the back of the impact point yield in tension, Finally the plastic hinge occurred at the pier bottom, the bending failure occurred mainly at the RC pier.

\section{Numerical models of the ship-pier collision}

In this paper, numerical models of the ship-pier collision were used for finite element modeling in the software package ANSYS. Calculations and analysis were developed in the software package LS-DYNA, and the post-processing of the calculation results were conducted in software package LS-PREPOST.

The modeling methods of reinforced concrete pier finite element method model in LS-DYNA mainly include two types: smeared model and discrete model. The main

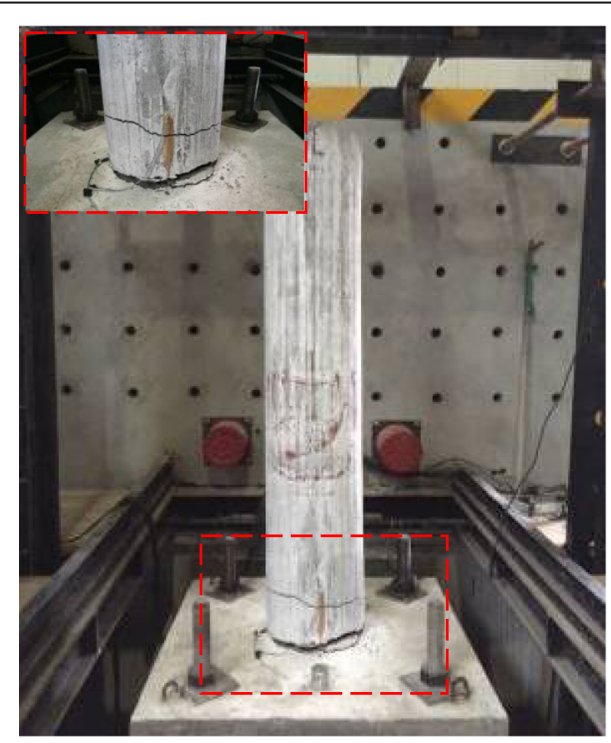

(a)

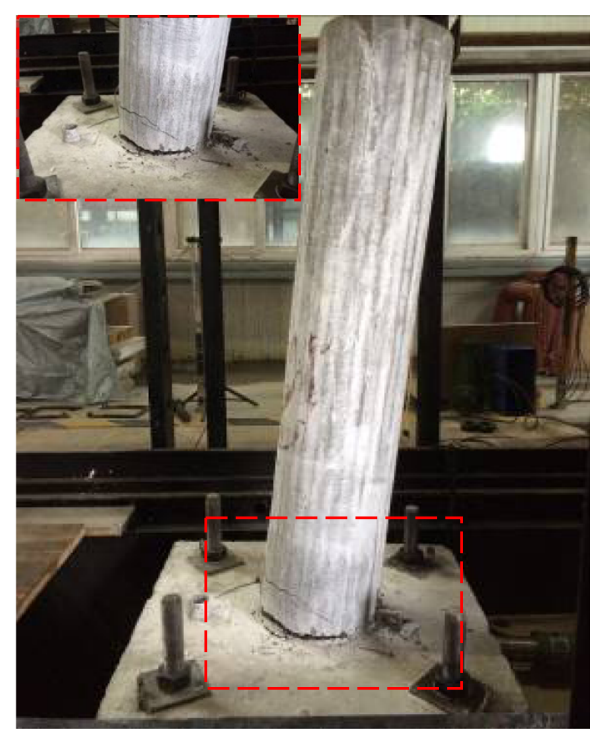

(b)

Fig. 10 Failure mode of pier: a front side; b lateral side 


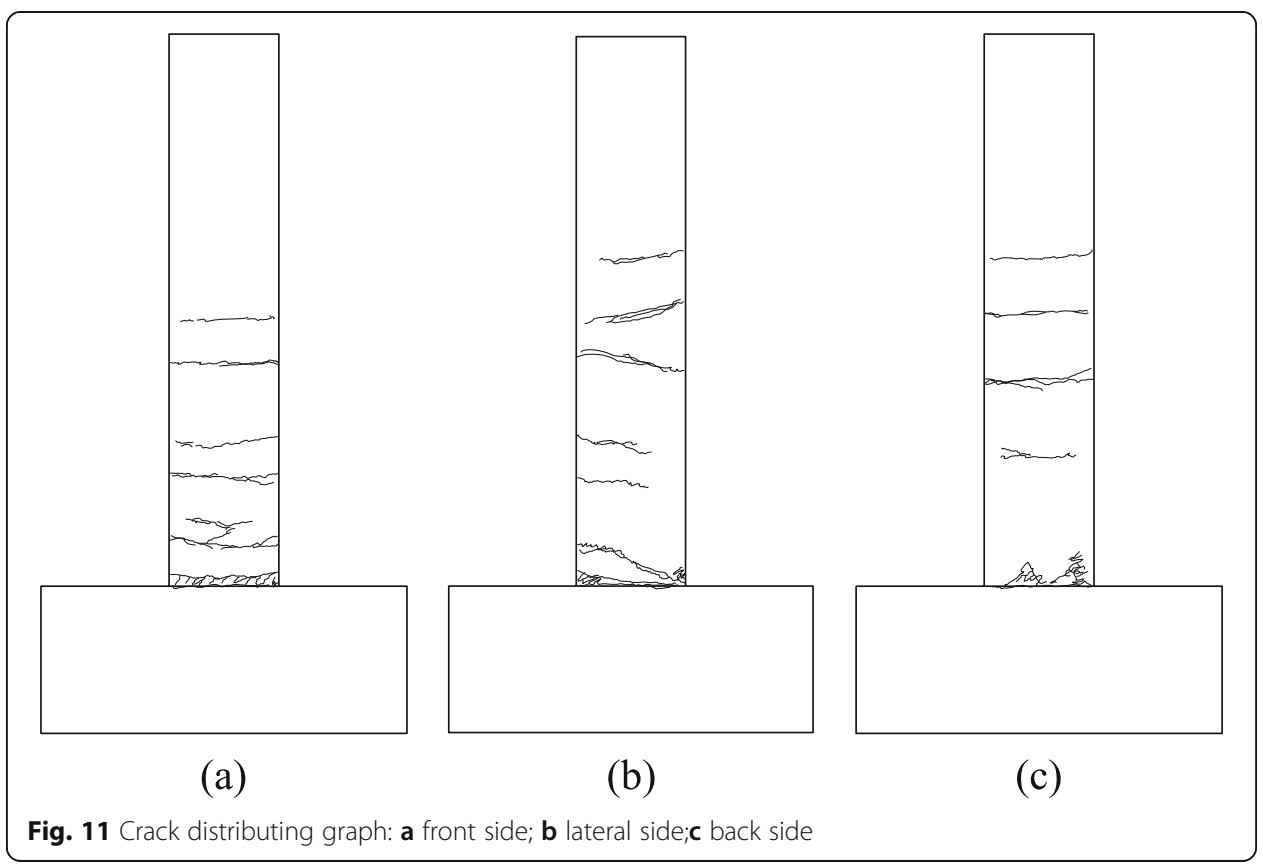

method of smeared model is to simulate the reinforced concrete with a material element, which takes into account the effect of the reinforcement (a single model of reinforcement is not employed). The advantage of this method is that it greatly simplifies the modeling process, and it is more convenient for the model of complex reinforced structures. However, its disadvantage is that it cannot simulate the real structure. The discrete model is to simulate the reinforcement and concrete with different elements and materials, and to ensure their joint work by sharing nodes. This

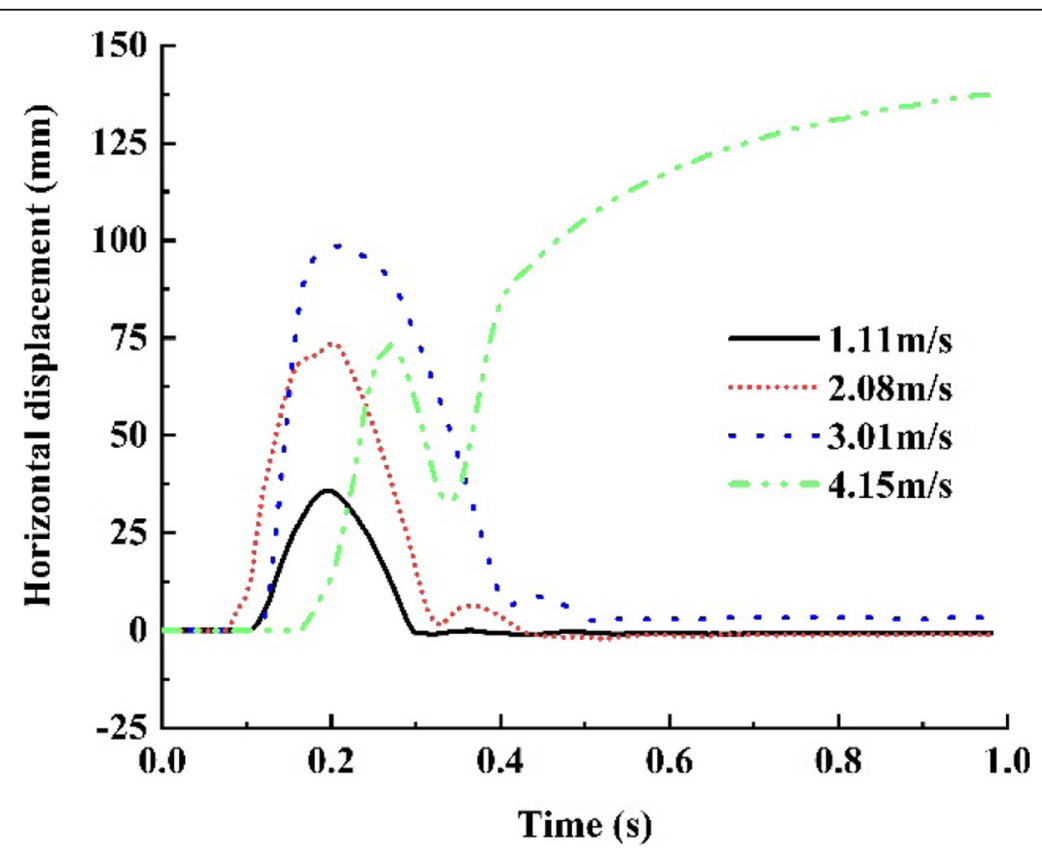

Fig. 12 Comparison of pier top displacement corresponding to different impact velocities 
method can simulate the prototype of reinforced concrete materials more realistically, however the modeling process is more complex. In this paper, the discrete model method is used to simulate reinforcement and concrete with different material models.

\subsection{Material models}

\subsubsection{The ship-collision FE model}

When the finite element model of ship-bridge collision was established in this study, the ship bow was simulated by shell elements, including outer panels, the inner transverse diaphragm, decks, etc. Because the rear part of the ship was far away from the impact area, there was no deformation actually occurred. Only stiffness and mass of the ship rear were provided. Therefore, the rigid solid element was used for the ship rear to simplify the simulation. During the impact process, as the bow entered the stage of material nonlinearity, the effect of strain hardening and strain rate on the yield strength of materials was considered. Therefore, the elastic-plastic material model.

* MAT_PLASTIC_KINEMATIC was used to model the ship bow, and the material * MAT_RIGID was used to model the ship rear. The modified Cowper-Symonds constitutive equation was used in the bow model. The parameters are as follows: strengthening parameter beta $\beta=0 ; D=40, q=5$; static yield stress $\sigma_{0}=310 \mathrm{MPa}$; maximum failure strain $\varepsilon=0.35$.

\subsubsection{The rigid head FE model}

No deformation of rigid head in the impact was taken into account, therefore, the material * MAT_RIGID was used to model the rigid head in LS-DYNA. The bottom and top of the ship bow were assumed to be fixed and free, respectively.

\subsubsection{The RC pier FE model}

A discrete model of the reinforced concrete pier was utilized, as shown in Fig. 13. The elastic-plastic material model "MAT_PLASTIC_KINEMATIC, which is cost-effective to simulate isotropic and kinematic hardening plasticity including strain rate effects, was utilized to model the reinforcements in the pier column. The modified CowperSymonds constitutive equation was used in the pier reinforcements. The values of the parameters are as follows: strengthening parameter $\beta=0 ; D=40, q=5$; static yield stress $\sigma_{0}=455.49 \mathrm{MPa}$. The material failure strain $\varepsilon$ of reinforcements is generally taken as $0.05 \sim 0.35$. The maximum failure strain $\varepsilon$ of the material taken in this paper is 0.35 .

The concrete material model used in this paper is the elastic-plastic damage cap model, the material model "MAT_SCHWER_MURRY_CAP_MODEL simulates the damage of concrete (Jiang et al. 2012). Grade 40 concrete was used as the strength parameter of concrete model, and the parameter values are shown in Table 3.

\subsection{Simplified treatment of added mass}

The water medium around the ship participates in the absorption of collision energy during the ship traveling. The interaction between ship and water medium during shippier collision can be treated by adding mass. The rigid displacement occurs mainly in the direction of collision, and at this time, the influence of the surrounding water medium is relatively small. The value of added mass depends on the type of ship and 
the collision history, etc. It is very difficult to calculate the added mass of fluid accurately, which is usually simplified. Mass is added to the impact ship in the form of additional mass density, generally taking $2 \% \sim 7 \%$. In this paper, $4 \%$ of the ship mass is taken as the added mass in the finite element simulation (Motora and Fujino 1971). Therefore, this ship model has a total weight of 1.49 tons including added mass.

\subsection{Element selection and mesh generation}

Solid164 three-dimensional solid element was used for rigid impact and reinforced concrete components. There are 8 nodes in this element and each node has three degrees of freedom of translation, velocity and acceleration in the direction of $\mathrm{x}, \mathrm{y}$ and $\mathrm{z}$. Beam element was utilized for the reinforcements of reinforced concrete columns. Shell 181 element was employed for the bow model, which was suitable for analyzing linear large rotation deformation and nonlinear large deformation, and shell structures with a certain thickness. It is a four-node element with six degrees of freedom for each node: the degree of freedom of displacement in the direction of $\mathrm{X}, \mathrm{Y}$ and $\mathrm{Z}$ and the degree of freedom of rotation around the axes of $\mathrm{X}, \mathrm{Y}$ and $\mathrm{Z}$.

It could be known that the stress of the pier and ship bow was large and concentrated through horizontal impact test. Therefore, these parts of the model needed to be refined, while the other parts could be roughly divided. Based on the above rules, different mesh sizes were adopted for the mesh generation of the pier and ship bow. Rigid material model was utilized for the cart, and the mesh generation did not affect the accuracy of calculation. Therefore, in order to save computing time, the impactor mesh size was divided into $10 \mathrm{~mm}$ tetrahedron, and the rest was used by mapping mesh generation.

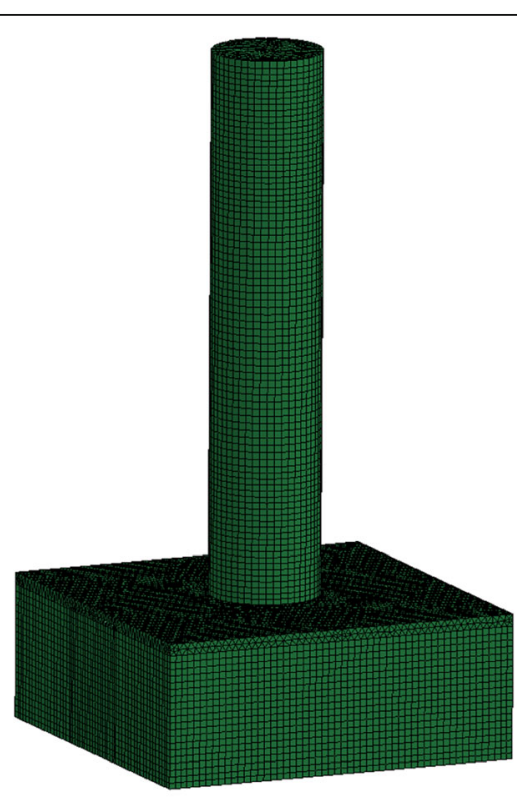

(a)

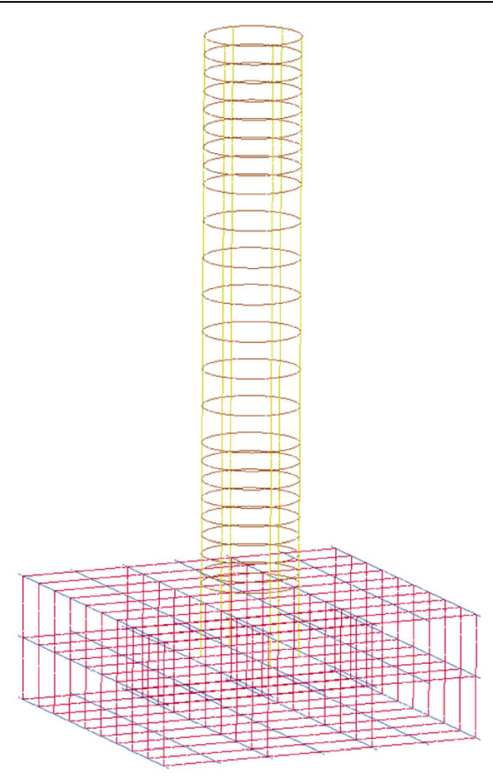

(b)

Fig. 13 FE model of RC pier:a FE model of concrete components; $\mathbf{b}$ FE model of reinforced bars 
Table 3 Parameters of elastoplastic damage cap model

\begin{tabular}{llllll}
\hline Parameter & value & Parameter & value & Parameter & value \\
\hline$a$ & 11.16 & $a_{1}$ & 0.82 & $a_{2}$ & 0.76 \\
$\theta$ & 0.3331 & $\theta_{1}$ & 0 & $\theta_{2}$ & 0 \\
$\lambda$ & 5.3731 & $\lambda_{1}$ & 0.2407 & $\lambda_{2}$ & 0.2562 \\
$\beta$ & 0.0338 & $\beta_{1}$ & 0.0104 & $\beta_{2}$ & 0.0089 \\
$X_{0}(\mathrm{MPa})$ & 89.14 & $W$ & 0.067 & $B^{-}$ & 0.1 \\
$D_{1}$ & $9.50 \mathrm{E}-04$ & $R$ & 2 & $A^{+}$ & 1 \\
$D_{2}$ & $1.68 \mathrm{E}-06$ & $A^{-}$ & 1 & $B^{+}$ & 0.3 \\
\hline
\end{tabular}

Notes: $a, \theta, \lambda$ and $\beta$ are compressive meridian parameters; $a_{1}, \theta_{1}, \lambda_{1}$ and $\beta_{1}$ are shear meridian parameters; $a_{2}, \theta_{2}, \lambda$ and $\beta$ are tensile meridian parameters; $X_{0}$ is uniaxial compressive strength; $D_{1}, D_{2}$ and $W$ are the cap shape and position parameters; $A^{-}, B^{-}, A^{+}$and $B^{+}$are material damage parameters

\subsection{Boundary condition and contact definition}

In order to accurately simulate the stress on pier and the constraint conditions of the model test, the fixed constraint was adopted under the base and the axial load on the pier top was applied in the form of surface load in the finite element model.

It was important for the treatment of sliding and contact at the interfaces between different elements in FE modeling. In this study, there were two contacts: one was between the impactor and the concrete and another was between the impactor and the reinforcement. Therefore, two contact algorithms, namely "CONTACT_AUTOMATIC_SURFACE_TO_SURFACE (ASTS) and "CONTACT_AUTOMATIC_NODES _TO_SURFACE(ANTS) were employed in the simulations, respectively. In this study, the dynamic and static friction values were both set to 0.3 for these surfaces between impactor and the concrete. And the contact algorithm ANTS with a contact friction value of 0.21 was selected for these surfaces between the impactor and the reinforcement.

\subsection{FE model calibration and validation}

To validate the reliability of the FE model to predict the pier response when ship pier was subjected to impact, the FE model was built to simulate horizontal impact tests. Ship-pier collisions were carried out with different velocities in this study. Results of resultant impact force at the impact area and the pier pop displacement obtained from tests were compared with numerical results.

As shown in Fig. 14, the FE simulation of the pier model impact with the ship bow was carried out, and the impact velocity of $4.22 \mathrm{~m} / \mathrm{s}$ was considered. Figure 15(a) shows that the peak impact force of the experimental value and FE value were $64.50 \mathrm{kN}$ and $72.81 \mathrm{kN}$ respectively, with the deviation of $12.9 \%$. And Fig. 15(b) shows that the pier top displacement of the experimental value and FE value were $8.0 \mathrm{~mm}$ and $8.4 \mathrm{~mm}$ respectively, with the deviation of $5 \%$. The deviation between the experimental value and the finite element value are within $20 \%$.

From the comparison of impact force and pier top displacement, it can be seen that the peak value and duration of FE impact force are in good agreement with the test results, and the FE and the test displacement curve are in good agreement before the peak deflection. The error of the descending section is mainly caused by the elastic deformation of the pier. When the velocity of the pier is greater than that of the impactor, 
the impact force and displacement both decrease, and the velocity of impactor and pier continue to decrease at any time. When the velocity of the pier is slower than that of the impactor, the impact force and displacement begin to increase. The above process continues as the impactor rebounds and separates, and the impact force becomes 0 when no more contact occurs.

As shown in Fig. 16, the distribution of effective plastic strain is closely related to the distribution of concrete cracks. The distribution of effective plastic strain obtained from the numerical simulation is in good agreement with the distribution of cracks observed in the test, and the bow collapse deformation is basically consistent with the failure of the test bow.

As shown in Fig. 17, the FE simulation of impact the pier model with rigid head was carried out with four impact velocities, $1.11 \mathrm{~m} / \mathrm{s}, 2.08 \mathrm{~m} / \mathrm{s}, 3.01 \mathrm{~m} / \mathrm{s}$ and $4.15 \mathrm{~m} / \mathrm{s}$. The peak impact force and the maximum displacement of the pier flange obtained from FE model simulation results are compared with the experimental results in Table 4. Except the FE simulation of pier impact at $4.15 \mathrm{~m} / \mathrm{s}$, where the displacement of the pier flange is too large, the deviations between the experimental value and the finite element value at $1.11 \mathrm{~m} / \mathrm{s}, 2.08 \mathrm{~m} / \mathrm{s}, 3.01 \mathrm{~m} / \mathrm{s}$ are all within $20 \%$. As shown in Fig. 18, the damage crack distribution of numerical simulation is in good agreement with the test results.

Fig. 19(a) shows the variation curve of peak impact force with impact velocity. When the impact velocity is less than $2.08 \mathrm{~m} / \mathrm{s}$, the impact force is proportional to the impact velocity. From the finite element simulation and the experimental phenomena, it is observed that the cracks at the pier bottom obviously occurred. When the impact velocity was $3.01 \mathrm{~m} / \mathrm{s}$, the plastic hinge was formed at the pier bottom, which led to the change of stress form of pier. At that time, the pier was destroyed and the peak impact force decreased instead of increasing. When the impact velocity is $4.15 \mathrm{~m} / \mathrm{s}$, the peak impact force decreases further. Figure 19(b) shows the relation curve between the pier top displacement and impact velocity and the comparison of numerical and experimental results. As shown in the graph, the two curves are basically the same, which shows a linear relationship between the pier top displacement and the impact velocity. However, the failure strain increases after the failure of the FE model element, which leads to the further increase of the deviation with experimental results.

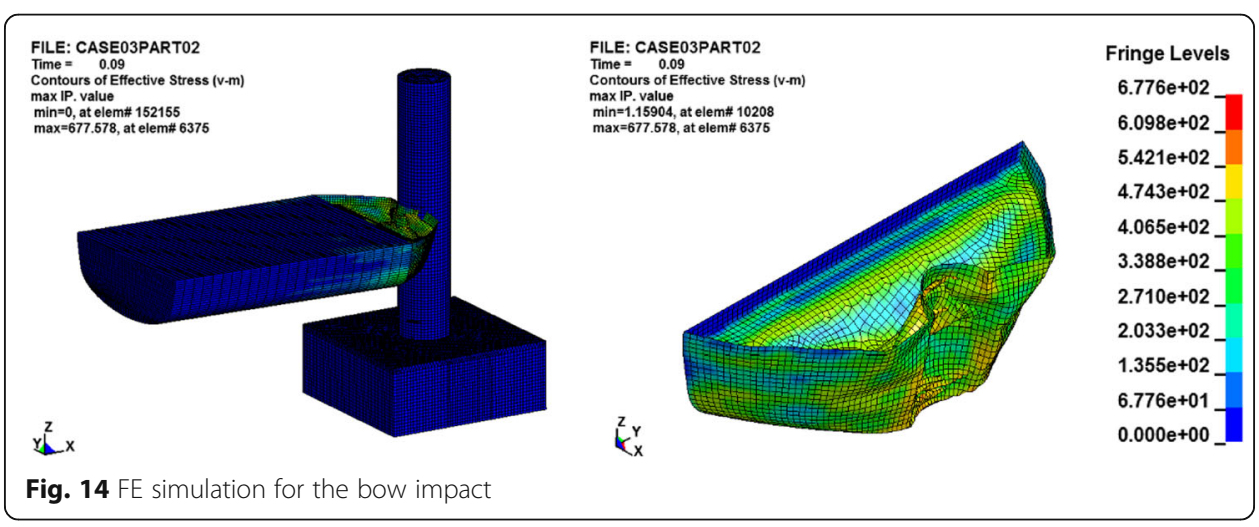




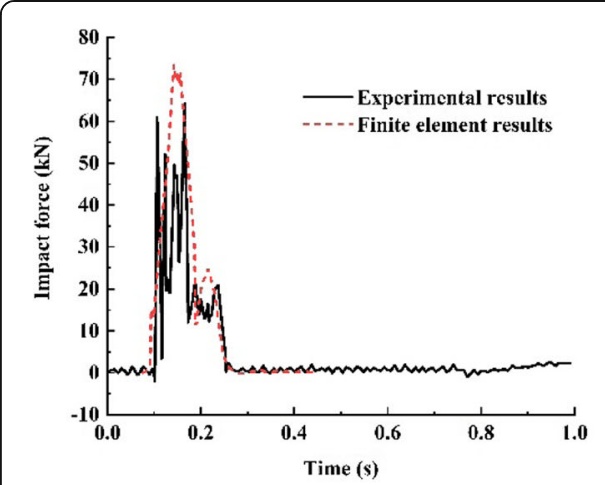

(a)

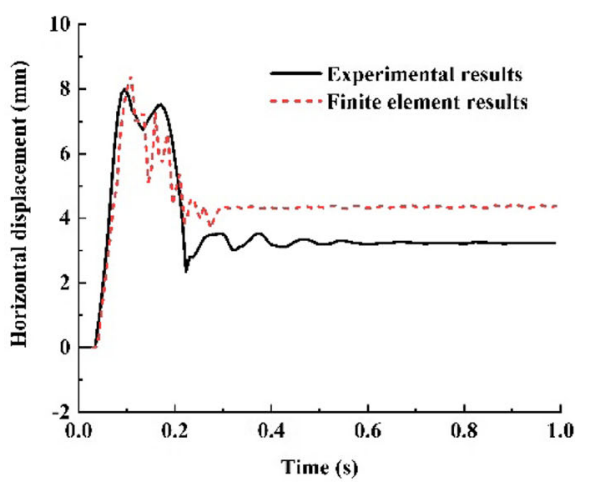

(b)

Fig. 15 Comparison of pier top displacement corresponding to different impact velocities: a impact force; b pier displacement

\section{Impact force results from empirical formula}

\subsection{Empirical formula}

In the light of the test and numerical results, the empirical design impact loads prescribed by Eurocode (Vrouwenvelder 1998) and AASHTO LRFD Bridge Design Specifications (AASHTO 2009) were evaluated.

The design impact force F can be determined in accordance with the Eurocode as

$$
F=V \cdot \sqrt{K M}
$$

where $V$ is the velocity of ship; $M$ is the mass of ship that is 1489.9 tons in this study; and $K$ is the stiffness of ship bow that is taken as $5 \mathrm{MN} / \mathrm{m}$ for inland ship or $15 \mathrm{MN} / \mathrm{m}$ for seagoing vessel, and $5 \mathrm{MN} / \mathrm{m}$ is assumed here.

The design impact force Ps can be determined from the empirical formula in the AASHTO LRFD Bridge Design Specifications as

$$
P_{S}=1.2 \times 10^{5} V(D W T)^{1 / 2}
$$

where $V$ is the velocity of ship; and $D W T$ is the deadweight tonnage of the ship taken as 100 tons in this study.
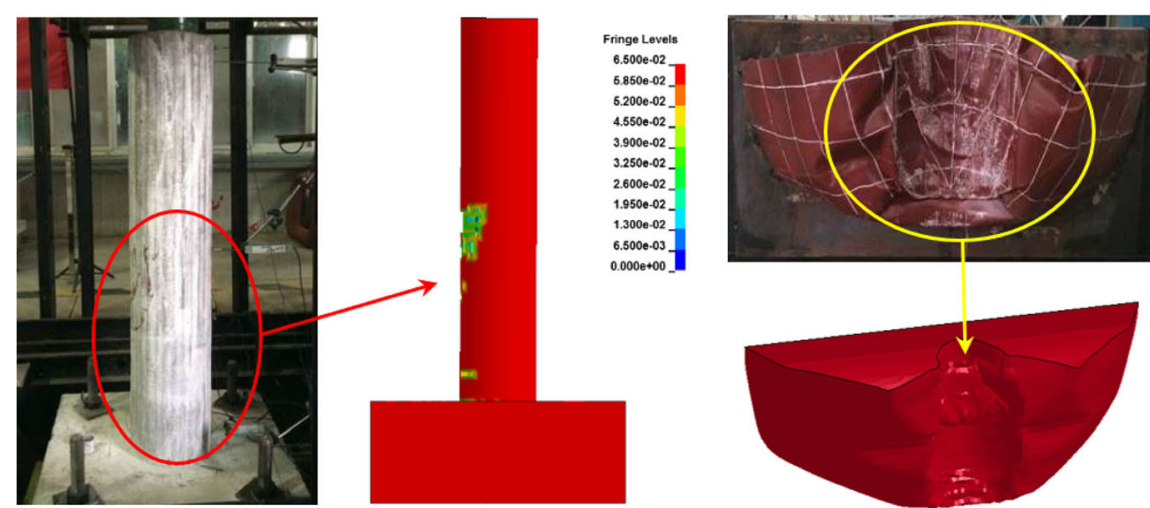

Fig. 16 Failure modes comparison between pier and bow 


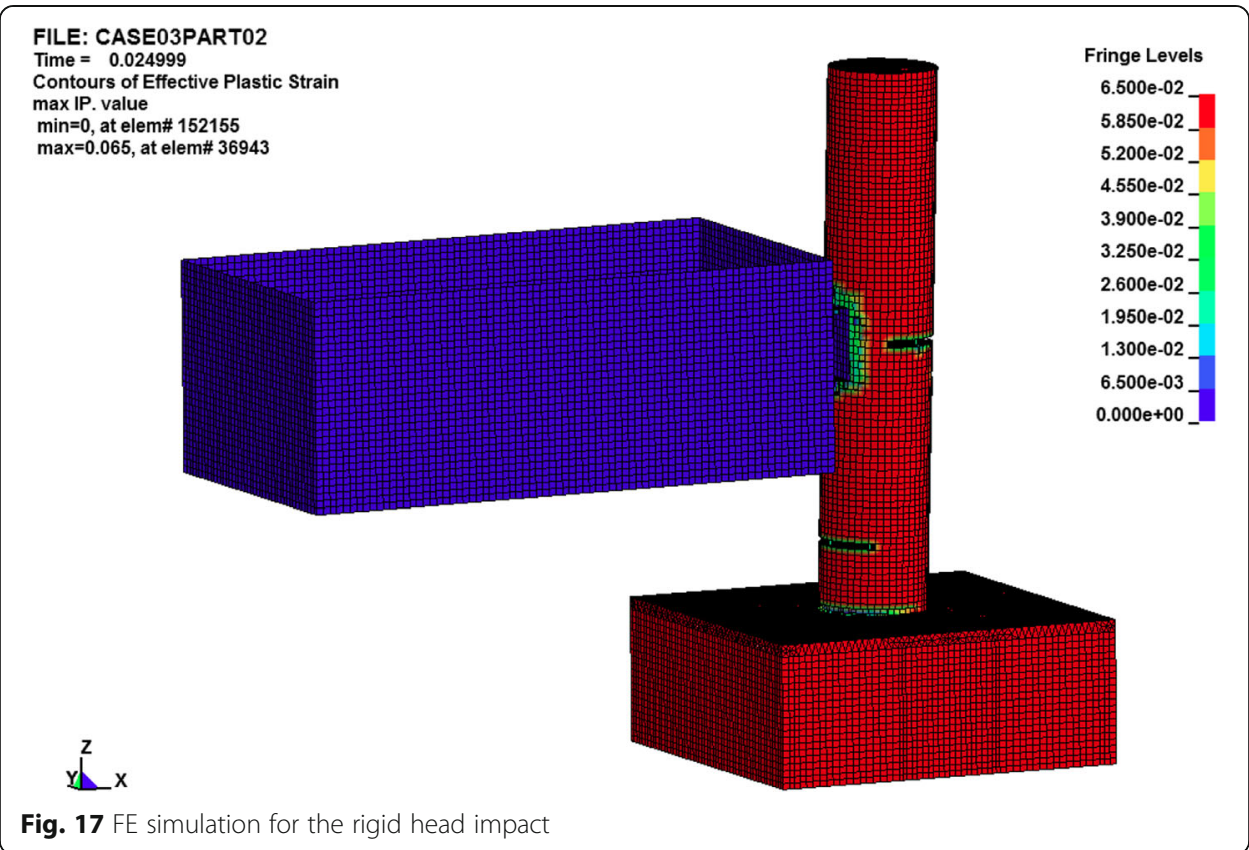

\subsection{Comparison of simulation results with empirical formula}

On the basis of the similarity ratio theory, the similarity ratios of the length and force are 1:10 and 1:100, respectively. As shown in Table 5, the bow impact force of the prototype pier obtained from the experimental test based on the similarity ratio is 6.45 $\mathrm{MN}$, which is $11.4 \%$ lower the FE result, and the deviations of the rigid head impact force between the experimental value and the finite element value are all within $20 \%$, indicating the scaled model tests are reliable. The results from the empirical formula for the design impact force provided by Eurocode and AASHTO LRFD Bridge Design Specifications are listed in Table 5 for comparison. The design impact force based on AASHTO LRFD Bridge Design Specifications is higher than that based on the Eurocode. When the pier is impacted by the ship, the design impact force of the Eurocode is closer to the simulation results. When the pier is impacted by the rigid head, the design impact force of the AASHTO code is closer to the simulation results.

\section{Analysis of ultimate bearing capacity of RC pier}

\subsection{Fiber model calculation assumption}

The piers are equipped with longitudinal reinforcement and spiral stirrup. In normal operation, the spiral stirrups restrain the core concrete and make it in three-way

Table 4 Comparison between experimental and FE results

\begin{tabular}{|c|c|c|c|c|c|c|}
\hline \multirow{2}{*}{$\begin{array}{l}\text { Impact } \\
\text { velocity } \\
(\mathrm{m} / \mathrm{s})\end{array}$} & \multicolumn{2}{|c|}{ Impact force $(\mathrm{kN})$} & \multirow[t]{2}{*}{ Error } & \multicolumn{2}{|c|}{ Pier top displacement (mm) } & \multirow[t]{2}{*}{ Error } \\
\hline & Test value & FE value & & Test value & FE value & \\
\hline 1.11 & 90.40 & 82.53 & $8.71 \%$ & 35.50 & 37.57 & $5.83 \%$ \\
\hline 2.08 & 176.30 & 151.65 & $13.98 \%$ & 73.30 & 65.21 & $11.04 \%$ \\
\hline 3.01 & 148.70 & 152.80 & $2.76 \%$ & 98.20 & 116.79 & $18.93 \%$ \\
\hline 4.15 & 102.60 & 96.28 & $6.16 \%$ & 137.10 & 178.53 & $30.22 \%$ \\
\hline
\end{tabular}




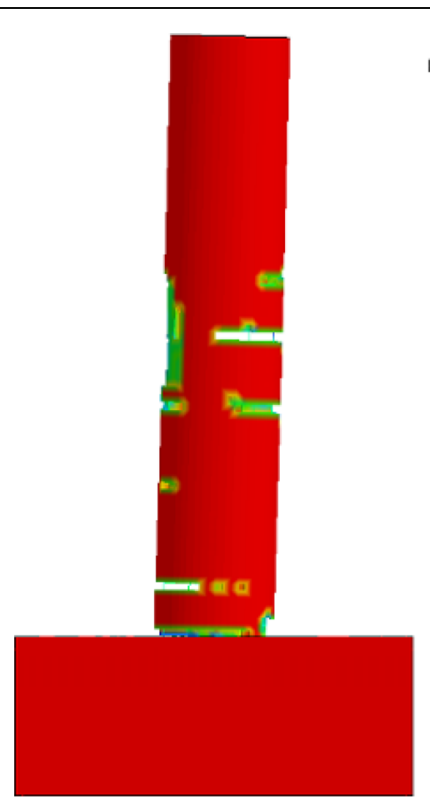

(a)

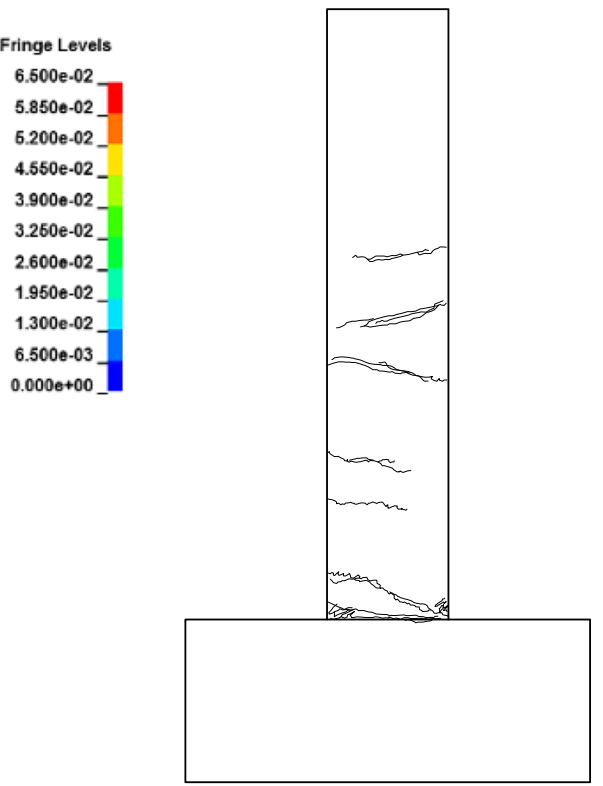

(b)

Fig. 18 Comparison between FE analysis and model test: a FE analysis; b model test

compression state, so as to improve the compressive strength of concrete in this part. When the longitudinal reinforcement yields, the concrete cover will crack and peel off because it is not restrained; when the piers are damaged, the core concrete will be crushed and the concrete cover will be completely broken. Based on the fiber model, the nonlinear analysis of circular section RC pier was carried out, and the ductility and ultimate bearing capacity of circular section pier were analyzed.

\subsection{Fiber model building and analysis}

The pier section is divided into grids, and the reinforced fiber and concrete fiber are surrounded in each grid. Different stress-strain relationships are given to different fibers, that is, the stress-strain relationship is given to confined concrete by core

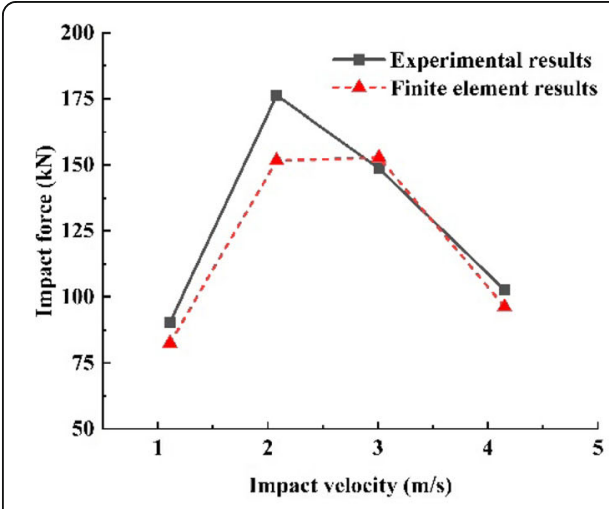

(a)

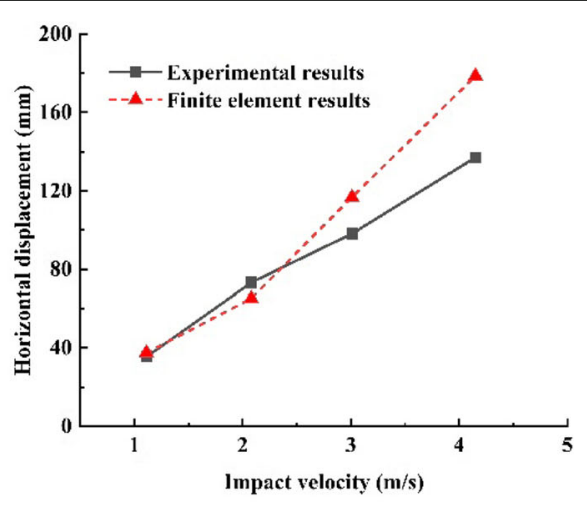

(b)

Fig. 19 The variation curve with impact velocity: a impact force; b pier top displacement 
Table 5 Comparison between results from test, FE simulation and empirical formulae

\begin{tabular}{lllllllll}
\hline $\begin{array}{l}\text { Test } \\
\text { condition }\end{array}$ & $\begin{array}{l}\text { Impact } \\
\text { velocity } \\
(\mathrm{m} / \mathrm{s})\end{array}$ & $\begin{array}{l}\text { Test } \\
\text { result } \\
\mathrm{P}_{\mathrm{T}}(\mathrm{MN})\end{array}$ & $\begin{array}{l}\mathrm{FE} \\
\text { result } \\
\mathrm{P}_{\mathrm{F}}(\mathrm{MN})\end{array}$ & $\begin{array}{l}\text { Eurocode } \\
\mathrm{P}_{\mathrm{E}} \\
(\mathrm{MN})\end{array}$ & $\begin{array}{l}\text { AASHTO LRFD Code } \\
\mathrm{P}_{\mathrm{A}} \\
(\mathrm{MN})\end{array}$ & $\begin{array}{l}\mathrm{P}_{\mathrm{T}} \\
/ \mathrm{P}_{\mathrm{F}}\end{array}$ & $\begin{array}{l}\mathrm{P}_{\mathrm{F}} \\
/ \mathrm{P}_{\mathrm{E}}\end{array}$ & $\begin{array}{l}\mathrm{P}_{\mathrm{F}} \\
/ \mathrm{P}_{\mathrm{A}}\end{array}$ \\
\hline $\mathrm{A}-1$ & 4.22 & 6.45 & 7.28 & 11.52 & 16.01 & 0.89 & 0.63 & 0.46 \\
B-1 & 1.11 & 9.04 & 8.25 & 3.02 & 4.21 & 1.09 & 2.73 & 1.95 \\
B-2 & 2.08 & 17.63 & 15.17 & 5.67 & 7.89 & 1.16 & 2.67 & 1.92 \\
B-3 & 3.01 & 14.87 & 15.28 & 8.22 & 11.42 & 0.97 & 1.85 & 1.33 \\
B-4 & 4.15 & 10.26 & 9.63 & 11.32 & 15.74 & 1.06 & 0.85 & 0.61 \\
\hline
\end{tabular}

concrete, the stress-strain relationship is given to ordinary concrete by concrete cover, and the constitutive relationship is given to reinforcement by reinforcement.

The FE simulation adopted the fiber beam element model. Based on the stress-strain constitutive relationship of the element material, the section is divided into constrained concrete fiber element, unconstrained concrete element and reinforced fiber element. Because the stress-strain relationship of confined concrete is quite different from that of ordinary concrete. The ordinary concrete adopted a quadratic parabola and oblique straight concrete constitutive model proposed by American scholar Hongnestad, as shown in the Fig. 20(a). For confined concrete, the constitutive model of concrete confined proposed by Mander was used (Mander and Priestly 1984), as shown in the Fig. 20(b). The stress-strain relationship of reinforcement adopted the ideal elasticplastic hardening model. The material properties are shown in Table 6.

According to the cross-section size of the circular pier model, the cross-section analysis software Xtract was used to establish the pier section model and divide the unit, as shown in the Fig. 21. It is obtained that termination of analysis of moment - curvature occurred when confined C40 reached a compressive strain of 0.01017. As shown in the Fig. 22, effective yield moment is $27.24 \mathrm{kN} \cdot \mathrm{m}$ and ultimate yield moment is 36.91 $\mathrm{kN} \cdot \mathrm{m}$.

\subsection{Comparison and analysis of bearing capacity of bridge pier}

Due to the horizontal impact of the bridge pier, the bridge pier is an eccentric compression member at this time. According to the Chinese bridge design code (Ministry of Communications of the People's Republic of China 2015), the bearing capacity of the normal section of the pier is calculated according to the following formula:

$$
M \leq B r^{3} f_{c d}+D \rho r^{3} f_{s d}^{\prime}
$$

where $M$ is section moment; $B$ and $D$ is the calculation coefficient of the bearing capacity of the concrete and longitudinal reinforcement, respectively; $r$ is the radius of the circular section; $f_{c d}$ is the compressive strength of the concrete; $\rho$ is the reinforcement ratio of the longitudinal reinforcement, and $f_{s d}$ ' is the yield strength of the longitudinal reinforcement.

According to two methods, the moment of circular section can be calculated as shown in Table 7. It shows that the ultimate moment of Section curvature method is $15.31 \%$ higher than that of the code method, which shows that the circular section has the ability to continue bearing horizontal capacity Therefore, it can be multiplied by 1.15 to improve the coefficient on the basis of the results of the anti-collision force calculated by the code method, which is used to indicate the restraint effect of the stirrup. 


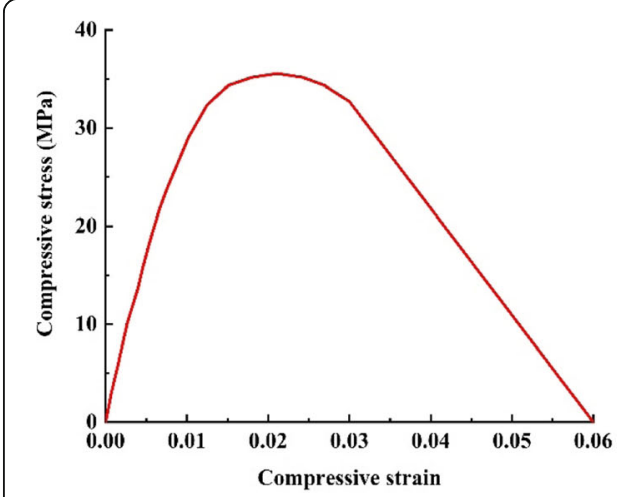

(a)

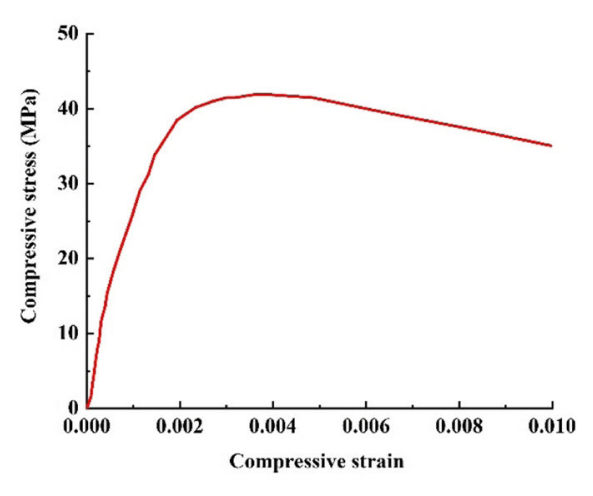

(b)

Fig. 20 Stress-strain curve for concrete: a unconfined concrete; b confined concrete

Under axial loading, the bearing capacity of oblique section of RC circular pier consists of three parts: contribution of axial loading to shear strength, shear capacity provided by concrete and shear capacity provided by stirrups. Before the oblique crack occurs, the concrete mainly resists the shear force, and after the oblique crack occurs, the concrete and stirrups jointly bear the shear force. According to the code for design of concrete structures (Ministry of Communications of the People's Republic of China 2010), the shear capacity formula of RC circular section is as follows:

$$
\begin{aligned}
& V_{u}=\frac{1.75}{\lambda+1} b h_{0} f_{t}+f_{y v} \frac{A_{s v}}{S} h_{0}+0.07 N \\
& b=1.76 r, h_{0}=1.6 r
\end{aligned}
$$

where $\lambda$ is shear span ratio of calculational section; $b$ is section width; $h_{0}$ is effective height of section; $f_{t}$ is tensile strength of concrete; $f_{y v}$ is yield strength of stirrup; $A_{y v}$ is area of stirrup section; $S$ is stirrup spacing; $N$ is axial loading; $r$ is sectional radius.

According to the code formulae, the shear strength of pier section is $86.47 \mathrm{kN}$. According to structural mechanics analysis, it is assumed that the axial force is ignored and the lateral stiffness of the pier is large, and the influence of rotational inertia is not considered. At this time, the simplified model of the pier is shown in Fig. 23. Through structural force analysis, the maximum section bending moment occurs at the bottom of the pier.

When the bending deformation of the pier mainly occurs, the pier resistance $F$ is as follows:

Table 6 The material properties

\begin{tabular}{lll}
\hline Material & Parameter & Magnitude \\
\hline Unconfined concrete & Compressive strength & $34.90 \mathrm{MPa}$ \\
& Yield strain & 0.001 \\
Confined concrete & Compressive strength & $40.84 \mathrm{MPa}$ \\
& Yield strain & 0.004 \\
Reinforcement & Yield strength & $454.99 \mathrm{MPa}$ \\
& Ultimate strength & $770.29 \mathrm{MPa}$ \\
\hline
\end{tabular}




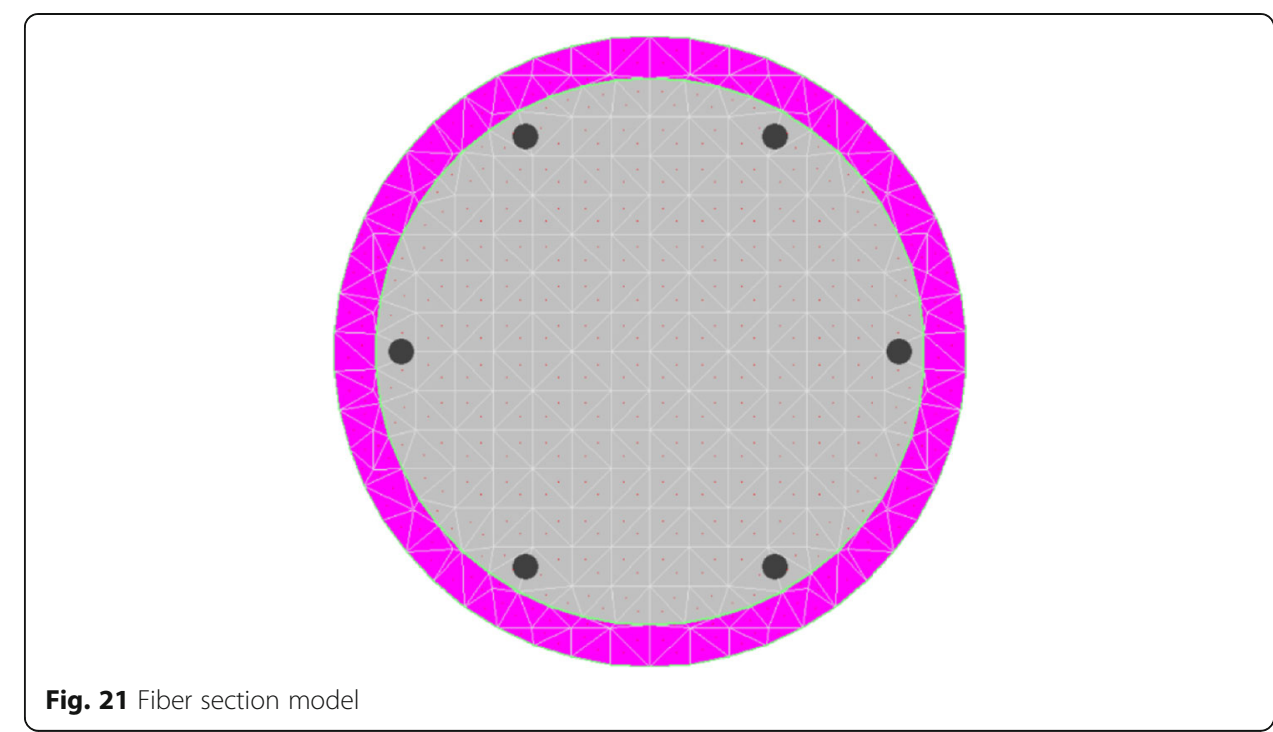

$$
F=\frac{M}{L}
$$

When the pier is directly damaged by shear, the pier resistance P is as follows:

$$
P=V
$$

It is calculated that the resistance $\mathrm{F}$ of the pier is $61.51 \mathrm{kN}$ and $\mathrm{P}$ is $86.47 \mathrm{kN}$. When the pier was subjected to impact by ship show, the peak impact force was $64.50 \mathrm{kN}$. At this time, the theoretical impact force value of $61.51 \mathrm{kN}$ is less than the test value of $64.50 \mathrm{kN}$, therefore, bending failure of the pier mainly occurs, which is basically consistent with the test phenomenon that slight scratches occurred at the impact point and the bottom of the pier. When the pier was subjected to impact by the rigid head, the theoretical impact forces of $61.51 \mathrm{kN}$ and $86.47 \mathrm{kN}$ are greater than all test values,

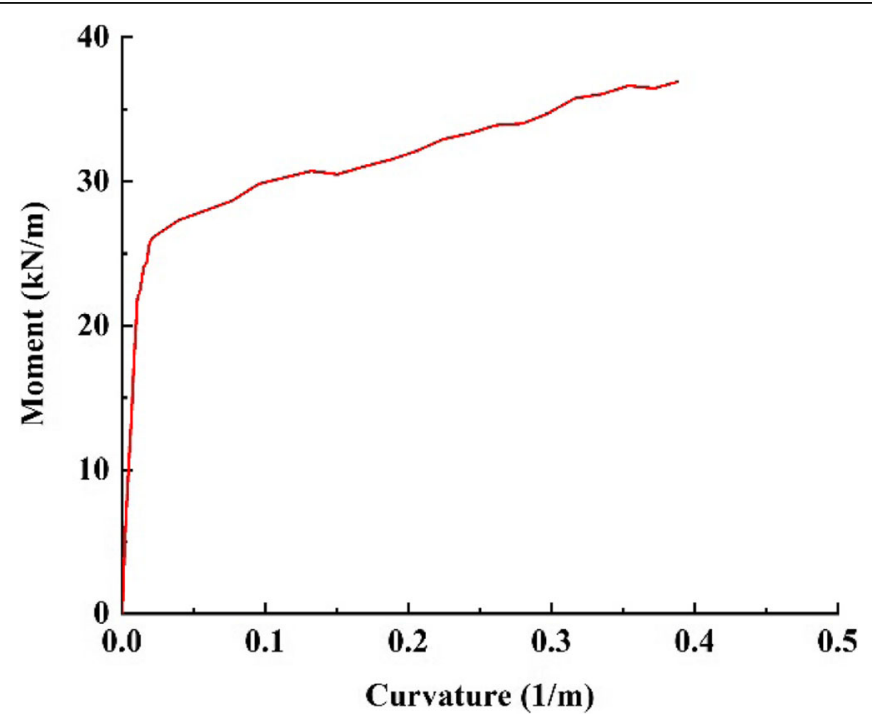

Fig. 22 Moment-curvature curve of the pier 
Table 7 Ultimate bearing moment of circular section by the two methods

\begin{tabular}{lccr}
\hline Axial loading $(\mathrm{kN})$ & \multicolumn{2}{l}{ Ultimate bearing moment $(\mathrm{kN} \cdot \mathrm{m})$} & Deviation \\
\cline { 2 - 3 } & Section-curvature method & Code method & \\
\hline 14.70 & 36.91 & 32.01 & $15.31 \%$ \\
\hline
\end{tabular}

so piers mainly suffer from bending failure. Therefore, it is shown that the theoretical calculation of the pier resistance is reliable.

\section{Conclusions}

In this study, horizontal impact tests of ship-pier collision were conducted on a scaled circular reinforced concrete pier. Numerical model was developed and calibrated with the experimental results. The calibration results show that the current finite element model can accurately predict impact force time history and pier displacement. The following conclusions regarding the ship collisions can be drawn:

(1) The impact force and the dynamic response of piers under collision at different impact velocities and with the bow and rigid head are experimentally studied. Under the impact loading, the bending failure occurs mainly at the foot of circular $\mathrm{RC}$ pier model with the rigid head at the velocity of $4.15 \mathrm{~m} / \mathrm{s}$. The main failure mode is bending failure with localized concrete crushing.

(2) The bow impact time of $0.167 \mathrm{~s}$ is 2.1 times the rigid head impact time of $0.08 \mathrm{~s}$, and the rigid head impact force of $10.26 \mathrm{MN}$ is 1.6 times the bow impact force of 6.45 MN. It is concluded that the impact time is related to the stiffness of impactor and the impact duration becomes shorter with greater impactor stiffness. For the same specimen, the impact duration decreases with the increase of impact energy, and the pier top displacement increases with the increase of impact velocity.

(3) The FE simulation tests are in good agreement with the test results: the pier failure is basically consistent with the test phenomenon; the time-history curve of the impact force and the impact contact time are well verified with the test results; the errors of the impact force and the horizontal displacement of the pier top are generally less than $20 \%$, which is within the acceptable range. Thus, the applicability of the model in this paper is verified.

(4) The design impact force based on AASHTO LRFD Bridge Design Specifications is higher than that based on the Eurocode. When the pier is impacted by the ship, the design impact force of the Eurocode is closer to the simulation results. When the pier is impacted by the rigid head, the design impact force of the AASHTO code is closer to the simulation results.

(5) Considering the effect of spiral stirrups restraint on the improvement of concrete strength and ultimate strain, a section-curvature method was proposed. A fiber section model was established, and the bending moment-curvature analysis of circular was carried out by using the nonlinear constitutive model of reinforcement and concrete. The moment bearing capacity value calculated by the sectioncurvature method was $15.31 \%$ higher than that calculated by the Chinese bridge design code. 


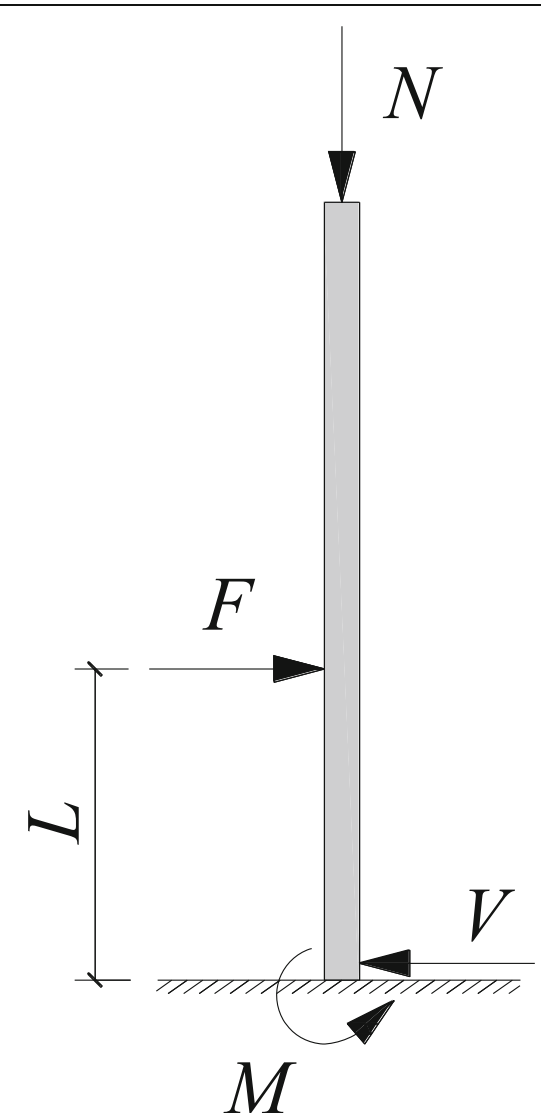

Fig. 23 The calculation diagram of bridge pier model

\section{Abbreviations}

RC: Reinforced concrete; FE: Finite element

\section{Acknowledgements}

The research described herein was supported by the National Natural Science Foundation of China (Grant No. 51778285), the Natural Science Foundation for distinguished Young Scholars of Jiangsu Province (Grant No. BK20190034) and Scientific Research Project of Hunan Provincial Department of Transportation (201916).

\section{Authors' contributions}

CZ carried out the literature investigation related to ship-pier collision, data curation and wrote the manuscript. HF reviewed and edited the manuscript, and was the corresponding author of this paper. LZ performed finite element simulation about ship-pier collision, YM carried out impact tests, WL mainly supervised. All authors read and approved the final manuscript.

\section{Funding}

The research described herein was supported by the National Natural Science Foundation of China (Grant No. 51778285), the Natural Science Foundation for distinguished Young Scholars of Jiangsu Province (Grant No. BK20190034) and Scientific Research Project of Hunan Provincial Department of Transportation (201916).

These funds have provided significant support to cost of experimental studies and the project design, and have played a significant role in the data curation, finite element simulation and manuscript writing, etc.

\section{Availability of data and materials}

We do not wish to share data, because the results of relevant tests and finite element analysis in this paper are based on the actual project about Wu-Song River Bridge to carry out the research.

\section{Competing interests}

We declare that we have no known competing financial interests or personal relationships that could have appeared to influence the work reported in this paper.

\section{Author details}

${ }^{1}$ College of Civil Engineering, Na njing Tech University, Nanjing 211816, China. ${ }^{2}$ China Railway Major Bridge Reconnaissance \& Design Institute Co., Ltd., Wuhan, China. 
Received: 15 April 2020 Accepted: 26 May 2020

Published online: 07 July 2020

\section{References}

AASHTO (2009) Guide specification and commentary for vessel collision design of highway bridges: American Association of State Highway and Transportation Officials

Consolazio G, Cook R, Cowan D, Bollmann H (2005) Assessing bridge pier response to barge collision loads. labse Symposium Report 90:9-16

Consolazio GR, Cowan DR (2003) Nonlinear analysis of barge crush behavior and its relationship to impact resistant bridge design. Comp struct 81:547-557

Consolazio GR, Cowan DR (2005) Numerically efficient dynamic analysis of barge collisions with bridge Piers. J Struct Eng 131 $1256-1266$

Demartino C, Wu J, Xiao Y (2017) Response of shear-deficient reinforced circular RC columns under lateral impact loading. Int $J$ Impact Eng 109:196-213

Do TV, Pham TM, Hao H (2018) Numerical investigation of the behavior of precast concrete segmental columns subjected to vehicle collision. Eng Struct 156(375-3):93

El-Tawil S, Severino E, Fonseca P (2005) Vehicle collision with bridge piers. J Bridg Eng 10:345-353

Fang H, Mao Y, Liu W, Zhu L, Zhang B (2016b) Manufacturing and evaluation of large-scale composite bumper system for bridge pier protection against ship collision. Compos Struct 158:187-198

Fang H, Zhu L, Au F (2016a) Precast concrete segmental bridge Piers under ship impact. Labse Symposium Report 106:683690

Jiang H, He S, Wang J (2012) Parameters determination of elasto-plastic damage cap model for concrete materials. J Vib Shock 31(15):132-139

Lin J, Zhang Z, Zhuo W (2003) Experimental study of force of ship collision with Houzhu bridge of Quanzhou. China J Highway Transport 2:58-61

LSTC (2007) LS-DYNA. Keyword user's manual. Version 971. Livermore software technology corporation

Mander JB, Priestly MJN (1984) Theoretical stress-strain model for confined concrete. J Struct Eng 114:1804-1826

Manuel L, Kallivokas LF, Williamson EB, Bomba M, Berlin KB, Cryer A, Henderson WR (2016) A probabilistic analysis of the frequency of bridge collapses due to vessel impact. Bridge Design

Ministry of Communications of the People's Republic of China (2010) GB 50010-2010, Code for design of concrete structures, 2010 (in Chinese)

Ministry of Communications of the People's Republic of China (2015) JTG D62-2015, Code for design of highway reinforced concrete and prestressed concrete bridges and culverts, 2015 (in Chinese)

Minorsky VU (1959) An analysis of ship collision with reference to protection of nuclear powered plants. J Ship Res 3:1-4

Motora S, Fujino M (1971) Equivalent added mass of ships in collision. The Japan Society of Naval Architects and Ocean Engineers 3(7):138-148

Sha Y, Hao H (2012) Nonlinear finite element analysis of barge collision with a single bridge pier. Eng Struct 41:63-76

Sha Y, Hao H (2013) Laboratory tests and numerical simulations of barge impact on circular reinforced concrete piers. Eng Struct 46:593-605

Sherif ET, Edward S, Priscilla F (2015) Vehicle collision with bridge Piers. J Bridg Eng 10(3):345-353

Tang EKC, Hao H (2010) Numerical simulation of a cable-stayed bridge response to blast loads, part I: model development and response calculations. Eng Struct 32:3180-3192

Travanca J, Hao H (2014) Numerical analysis of steel tubular member response to ship bow impacts. Int J Impact Eng 64:101121

Vrouwenvelder ACWM (1998) Design for ship impact according to Eurocode 1,Part 2.7, Ship Collision Analysis, A. A. Balkema, Rotterdam, pp 123-134

Wan Y, Zhu L, Fang H, Liu W, Mao Y (2019) Experimental testing and numerical simulations of ship impact on axially loaded reinforced concrete piers. Int J Impact Eng 125:246-262

Woisin G (1976) The collision tests of the GKSS. Jahrb Schiffbautechnischen Gesellschaft 70:465-487

Yang M, Qiao P (2010) Analysis of cushion systems for impact protection design of bridges against overheight vehicle collision. Int J Impact Eng 37:1220-1228

Zhao W, Qian J (2019) Performance of reinforced concrete pier columns subjected to lateral impact. Chinese J Eng 41:408415

\section{Publisher's Note}

Springer Nature remains neutral with regard to jurisdictional claims in published maps and institutional affiliations. 